\title{
Physiological Responses to Low-Volume Interval Training in Women
}

\author{
Lauren E. Skelly ${ }^{1}$, Celine Bailleul ${ }^{2}$ and Jenna B. Gillen ${ }^{2 *}$ (]
}

\begin{abstract}
Interval training is a form of exercise that involves intermittent bouts of relatively intense effort interspersed with periods of rest or lower-intensity exercise for recovery. Low-volume high-intensity interval training (HIIT) and sprint interval training (SIT) induce physiological and health-related adaptations comparable to traditional moderate-intensity continuous training (MICT) in healthy adults and those with chronic disease despite a lower time commitment. However, most studies within the field have been conducted in men, with a relatively limited number of studies conducted in women cohorts across the lifespan. This review summarizes our understanding of physiological responses to low-volume interval training in women, including those with overweight/obesity or type 2 diabetes, with a focus on cardiorespiratory fitness, glycemic control, and skeletal muscle mitochondrial content. We also describe emerging evidence demonstrating similarities and differences in the adaptive response between women and men. Collectively, HIIT and SIT have consistently been demonstrated to improve cardiorespiratory fitness in women, and most sex-based comparisons demonstrate similar improvements in men and women. However, research examining insulin sensitivity and skeletal muscle mitochondrial responses to HIIT and SIT in women is limited and conflicting, with some evidence of blunted improvements in women relative to men. There is a need for additional research that examines physiological adaptations to low-volume interval training in women across the lifespan, including studies that directly compare responses to MICT, evaluate potential mechanisms, and/or assess the influence of sex on the adaptive response. Future work in this area will strengthen the evidence-base for physical activity recommendations in women.
\end{abstract}

Keywords: Interval exercise, Female, Sex differences, Cardiorespiratory fitness, Aerobic exercise, Insulin sensitivity, Insulin resistance, Glucose, Mitochondria, Skeletal muscle

\section{Key Points}

- Our understanding of physiological adaptations to interval training is primarily a result of research conducted in men, with a relatively limited number of studies conducted in women-only cohorts. Given the well-recognized sex-based differences in physiological systems at rest and in response to exercise, research findings in men may not be translatable to women.
- Research demonstrates that low-volume interval training is efficacious for improving cardiorespiratory fitness in women. However, research that examines improvements in glycemic control, insulin sensitivity and skeletal muscle mitochondrial responses in women-only cohorts is limited, with some studies reporting that women "respond less" compared to men.

- Further research is needed to clarify and advance our knowledge of interval training-induced responses in women of various ages, activity levels and health statuses, including studies that evaluate the influence of training prescription variables (e.g., training duration, protocol, exercise modality), and possible ergo-

\footnotetext{
${ }^{*}$ Correspondence: jenna.gillen@utoronto.ca

${ }^{2}$ Faculty of Kinesiology and Physical Education, University of Toronto,

Toronto, ON, Canada

Full list of author information is available at the end of the article
} 
genic or ergolytic variables (e.g., peri-exercise nutrition, supplements, hormonal contraceptives).

\section{Introduction}

Interval training refers to a style of exercise in which intermittent bouts of intense effort are interspersed with periods of lower-intensity exercise or rest for recovery. Research conducted over the past two decades has demonstrated the potency of interval training for eliciting physiological remodeling and improvements in indices of health that are comparable, or indeed superior, to those achieved with traditional forms of moderate-intensity continuous training (MICT) [1-5]. Interval training is also included as an exercise option within some physical activity guidelines $[6,7]$ and practiced widely by the general public, as evidenced by a top 5 ranking in the American College of Sports Medicine's annual survey of Worldwide Fitness trends from 2014 to 2021 [8]. Widespread interest in the application of interval training for improving health and fitness may stem, in part, from the time-efficient nature of low-volume protocols, considering 'lack of time' is a commonly reported barrier to regular physical activity participation [9].

Our understanding of physiological adaptations to interval training is primarily a result of research conducted in men or mixed-cohorts of men and women. A relatively limited understanding of interval training responses in women has recently been recognized [1013], which is perhaps unsurprising given that women are known to be underrepresented as participants in exercise physiology research [14-16]. However, there are wellrecognized sex differences in physiological systems at rest and in responses to acute exercise [17] that may result in sex-specific physiological and health-related adaptations to interval training. Thus, findings observed in men may not be translatable to women. Understanding biological similarities and differences between men and women is timely, as demonstrated by recent reviews summarizing sex-specific responses across a range of exercise-induced physiological, health and performance adaptations [12, $17-24]$.

Some of the most commonly reported health and performance-related adaptations to low-volume interval training include improvements in cardiorespiratory fitness (CRF), glycemic control and skeletal muscle mitochondrial content. Indeed, an interested reader is directed to recent comprehensive narrative reviews in this regard $[1,5,11,25]$. However, given that sex differences in physiology are increasingly recognized [17], the goal of this review is to summarize the evidence (or in some instances, lack thereof) for these physiological adaptations in women, and where relevant, identify similarities and differences to men. We identify gaps in our understanding of physiological and health-related responses to low-volume interval training in women and provide recommendations for how to advance the field in this regard. This review primarily focuses on research that examines aerobic-based low-volume interval training in participants who are healthy, with overweight/obesity or type 2 diabetes (T2D).

\section{Terminology and Methodology}

Interval training protocols within the literature vary in several factors, including the duration, intensity and number of intervals performed. High-intensity interval training (HIIT) consists of submaximal efforts that elicit $\geq 80 \%$ of maximal heart rate (HRmax), whereas sprint interval training (SIT) involves "all-out" or supramaximal efforts at an intensity $\geq 100 \%$ of the power output that elicits peak oxygen uptake ( $\mathrm{VO}_{2}$ peak) $[1,26]$. In addition, the duration of the intervals within a HIIT or SIT protocol is typically $\geq 1 \mathrm{~min}$ or $\leq 30 \mathrm{~s}$, respectively, and if the exercise protocol involves $<15 \mathrm{~min}$ of intense exercise, it is considered to be low-volume [5,27]. While the focus of this review is on adaptations to these time-efficient lowvolume HIIT and SIT protocols, some reference to studies using high-volume HIIT is provided, especially when conducted in unique women-only cohorts across the lifespan and/or when adaptations to low-volume protocols are lacking in women.

The present narrative review focuses primarily on data obtained from low-volume HIIT or SIT studies involving women-specific cohorts, as well as studies designed to address sex differences by directly comparing results between women and men. While a systematic review approach was not specifically employed, the information presented in this review was informed by literature searches conducted on MEDLINE and PubMed in February and March 2021 using keywords specific to the population (e.g., adult, female, women or type 2 diabetes), intervention (e.g., high intensity exercise, interval training, or sprint) and outcomes (e.g., aerobic capacity, cardiorespiratory fitness, oxygen consumption, glycemic control, insulin resistance, citrate synthase, mitochondrial content or mitochondrial proteins) of interest. The reference lists of relevant reviews returned by the literature searches were also examined for additional pertinent articles.

For areas where low-volume interval training studies in women-only cohorts are limited, the results of mixedsex cohort studies are presented, with acknowledgement that the evidence is from a mixed-sex study design. In many instances, the objectives of these studies do not include sex as an independent variable, and therefore, authors explore hypotheses in a mixed-cohort of men 
and women to enhance generalizability of the findings. This approach is commendable and often represents a well-considered design after evaluation of study timeline, funding and logistical constraints. However, mixed-sex cohorts in the field of exercise, cardiovascular and muscle physiology have been reported to be male dominant, with examples of studies published with $>4: 1$ male bias [14]. This obviously precludes an ability to properly assess or make inferences regarding responses in women alone. Thus, only data obtained from mixed-sex cohorts with a men-to-women ratio of $\leq 2: 1$ ( $\geq 33 \%$ of participants studied were women) are discussed in the present review. However, even in these instances, our ability to make definitive conclusions regarding the response in women is often limited owing to commonly small sample sizes in the field (e.g., $n=5$ of 10). Lastly, across the studies included in the present review, participants were referred to by a combination of gender (e.g., men, women) and/ or sex (e.g., male, female) terms. As we cannot ascertain whether these studies collected information regarding biological sex, the terms women and men are used to describe individuals in the present review, rather than female and male, consistent with others [23].

\section{Cardiorespiratory Fitness \\ Responses in Women}

Amongst the most well-documented physiological adaptations to interval training is an increase in CRF, most commonly measured with a $\mathrm{VO}_{2}$ peak test. Indeed, several systematic reviews and meta-analyses have concluded that HIIT and/or SIT improves CRF in adults who are young $[28,29]$, old [30,31], healthy [32-35] with overweight/obesity [36] or with T2D [37-39]. Improvements in CRF among inactive and active adults have also been reported in systematic reviews specifically examining interval training protocols that are low-volume [28, 33, $34,40]$. These findings have clinical and athletic performance implications, as CRF is a strong predictor of risk for cardiovascular disease and all-cause mortality [41, 42] and maximal aerobic capacity is a key determinant of endurance performance [43]. A limitation of many of these systematic reviews and meta-analyses, however, is the lower representation of women as participants, as noted in a meta-analysis by Bacon and colleagues [29]. Nonetheless, there are still a number of interventions in women-only cohorts that have documented improvements in CRF following low-volume interval training (Table 1). For example, a randomized controlled trial by Trilk and colleagues demonstrated that 4 weeks of lowvolume SIT, involving 4-7 $\times 30 \mathrm{~s}$ "all-out" cycle sprints performed 3 times per week, improved $\mathrm{VO}_{2}$ peak by $\sim 12 \%$ in young women with overweight/obesity [44]. Other studies have also found 7-22\% improvements in
$\mathrm{VO}_{2}$ peak following 3-10 weeks of low-volume interval training in women who are healthy [45-49] or with overweight $[50,51]$. The vast majority of low-volume HIIT or SIT studies in women have used cycling exercise, however, and it is unclear if other aerobic exercise modalities are as efficacious. Allison and colleagues [52] found that a low-volume SIT protocol, involving $3 \times 20 \mathrm{~s}$ stair climbing-based sprints, increased $\mathrm{VO}_{2}$ peak in inactive young women to a comparable extent as that previously observed with $3 \times 20$ s cycling sprints $(\sim 12 \%$; [53]) when performed thrice-weekly for 6 weeks. Improved CRF was also observed following 6-12 weeks of running-based SIT, involving $4-10 \times 30$ s sprints, in recreationally active women [54] and inactive women with overweight/obesity [55], and walking-based HIIT, involving $6 \times 1$ min efforts at $90 \%$ heart rate reserve, in older women (60-85 years) with T2D [56]. However, $\mathrm{VO}_{2}$ peak has been reported to be unchanged following 8-16 weeks of thrice-weekly 6-10 $\times 1$ min low-volume HIIT that used running/walking intervals in women who are older (60-75 years) [57] or with polycystic ovary syndrome [58]. Given these observations and considering that cycling equipment is inaccessible to some individuals, more research is warranted that evaluates the effect of low-volume HIIT/ SIT on CRF using diverse aerobic exercise modalities in women across the lifespan.

\section{Low-Volume Interval Training Versus MICT in Women}

Systematic reviews and meta-analyses have concluded that there is no difference in the efficacy of SIT and highvolume MICT for eliciting improvements in CRF in healthy adults $[28,59]$, and available primary evidence in women largely supports this conclusion. For example, 5 weeks of SIT, consisting of $60 \times 8 \mathrm{~s}$ cycling sprints interspersed with $12 \mathrm{~s}$ of recovery, or MICT, involving 40 min of cycling at $60-80 \% \mathrm{VO}_{2}$ peak, improved CRF to a comparable extent $(\sim 10 \%)$ in young inactive women with obesity, despite the MICT protocol eliciting a $\sim 2$-fold higher energy expenditure [60]. Similarly, other studies have reported no difference in the improvement in $\mathrm{VO}_{2}$ peak following low-volume interval training or MICT in young women with overweight/obesity [61-63], women who are postmenopausal (55-85 years) [64], and older women (60-85 years) with T2D [56]. A few studies have also compared improvements in CRF following 6-15 weeks of SIT with an energy expenditure-matched MICT protocol, demonstrating similar $[65,66]$ or superior [67] responses with SIT. Interestingly, a recent metaanalysis noted that women appeared to respond more favorably to SIT as opposed to MICT with respect to improvements in CRF [59]; however, the authors cautioned that the weighted effect size was small and a 
Table 1 Summary of adaptations related to cardiorespiratory fitness, insulin sensitivity, glycemic control, and mitochondrial content following common low-volume interval training protocols in women

\begin{tabular}{|c|c|c|c|}
\hline \multirow[t]{2}{*}{ Protocol } & \multicolumn{3}{|l|}{ Training duration } \\
\hline & 2-4 weeks & 5-11 weeks & $12-16$ weeks \\
\hline \multirow[t]{3}{*}{ Repeated Wingate SIT $(3-8 \times 30 \mathrm{~s})$} & $\uparrow \dot{\mathrm{V}} \mathrm{O}_{2}$ peak $[44,68,70,161]$ & $\uparrow \dot{\mathrm{V}}_{2}$ peak $[47,54,67]$ & $\uparrow \dot{\mathrm{v}} \mathrm{O}_{2}$ peak [55] \\
\hline & & $\begin{array}{l}\downarrow \mathrm{HbA1c}[162] \\
\leftrightarrow \operatorname{HbA} 1 \mathrm{c}[55]\end{array}$ & $\leftrightarrow \mathrm{HbA} 1 \mathrm{c}[55]$ \\
\hline & $\begin{array}{l}\uparrow \text { CS protein content }^{\dagger}[70] \\
\leftrightarrow \text { CS maximal activity }^{\dagger}[163] \\
\leftrightarrow \text { COXIV protein content }^{\dagger}[70]\end{array}$ & & \\
\hline \multirow[t]{3}{*}{$\begin{array}{l}\text { HIIT } \\
(10-12 \times 1 \mathrm{~min})\end{array}$} & $\begin{array}{l}\uparrow \dot{\mathrm{V}} \mathrm{O}_{2} \text { peak }[46,49,64,79] \\
\leftrightarrow \dot{\mathrm{V}}_{2} \text { peak }[164]\end{array}$ & $\uparrow \dot{V}_{2}$ peak $[49,50,165]$ & $\uparrow \dot{\mathrm{V}} \mathrm{O}_{2}$ peak [49] \\
\hline & & $\begin{array}{l}\leftrightarrow \text { OGTT insulin sensitivity [50] } \\
\downarrow \text { HOMA-IR [166] }\end{array}$ & $\downarrow$ HOMA-IR [110] \\
\hline & & $\begin{array}{l}\uparrow \text { CS maximal activity [50] } \\
\uparrow \text { COX activity [121] }\end{array}$ & \\
\hline \multirow{2}{*}{$\begin{array}{l}\text { Repeated sprint SIT } \\
\text { (6-20 s efforts) }\end{array}$} & & $\uparrow \dot{\mathrm{V}} \mathrm{O}_{2}$ peak $[60,167]$ & $\uparrow \dot{\operatorname{VO}} \mathrm{O}_{2}$ peak $[51,61,63,65,66,168]$ \\
\hline & & & $\begin{array}{l}\downarrow \operatorname{HOMA}-\mathrm{IR}[61] \\
\leftrightarrow \operatorname{HOMA}-I \mathrm{R}[65,66] \\
\downarrow \operatorname{HbA} 1 \mathrm{C}[100] \\
\leftrightarrow \operatorname{HbA} 1 \mathrm{C}[66]\end{array}$ \\
\hline \multirow[t]{3}{*}{$\begin{array}{l}\text { Reduced-volume SIT } \\
(\leq 10 \text { min session) }\end{array}$} & $\begin{array}{l}\uparrow \dot{\mathrm{V}} \mathrm{O}_{2} \text { peak }[62,72] \\
\leftrightarrow \dot{\mathrm{V}} \mathrm{O}_{2} \text { peak }[75]\end{array}$ & $\uparrow \dot{\mathrm{V}} \mathrm{O}_{2}$ peak $[52,53,69,71,75]$ & $\uparrow \dot{\mathrm{V}} \mathrm{O}_{2}$ peak $[10,75]$ \\
\hline & & $\begin{array}{l}\leftrightarrow \text { OGTT insulin sensitivity }[69,71] \\
\leftrightarrow 24 \text { h glucose mean or AUC }[53] \\
\downarrow \operatorname{HOMA}^{\prime} \mathrm{IR}^{\dagger}[53]\end{array}$ & $\leftrightarrow \operatorname{HOMA}-\mathbb{R}^{\dagger}[10]$ \\
\hline & & $\begin{array}{l}\uparrow \text { CS maximal activity }{ }^{\dagger}[53] \\
\uparrow \text { COXIV protein content }{ }^{\dagger}[53]\end{array}$ & \\
\hline \multirow[t]{3}{*}{ Reduced-volume HIIT (5 × $1 \mathrm{~min})$} & & $\uparrow \dot{\mathrm{V}} \mathrm{O}_{2}$ peak $[73,76]$ & \\
\hline & & $\begin{array}{l}\leftrightarrow \text { OGTT glucose and insulin AUC [73] } \\
\downarrow \text { HOMA-IR [76] } \\
\leftrightarrow \operatorname{HbA1C}[73]\end{array}$ & \\
\hline & & $\begin{array}{l}\uparrow \text { mitochondrial complex I, II, III, IV and V } \\
\text { protein content }{ }^{\dagger}[138] \\
\uparrow \text { CS maximal activity }{ }^{\dagger}[138]\end{array}$ & \\
\hline
\end{tabular}

Studies were conducted in women who were classified as healthy $[10,46,47,49,52,54,65,69-72,75,79,161]$, with overweight/obesity $[44,50,51,53,55,60-63$, $66,67,73,76,100,110,121,138,162,164,167,168]$ and/or type 2 diabetes $[100,162]$. For transparency, the same cohort of women was examined in the following pairs of references: $[50,121]$ and $[73,138]$. The symbol $(\dagger)$ denotes when a finding has only been documented in a study comparing responses between sexes and is based on a main effect of time for both men and women. Abbreviations: $\uparrow$ increase; $\downarrow$ decrease; $\leftrightarrow$ no change; AUC area under the curve; COXIV cytochrome $c$ oxidase subunit IV; CS citrate synthase; HbA1c glycated hemoglobin; HOMA-IR homeostatic model assessment of insulin resistance; OGTT oral glucose tolerance test; $\dot{\mathrm{V}} \mathrm{O}_{2}$ peak peak oxygen uptake

limited number of studies were available in the literature to conduct this sex-specific analysis.

\section{Sex-Based Comparisons}

Many investigations have reported no evidence of sex-based differences in low-volume interval traininginduced improvements in CRF [53,68-73], although this is not a universal finding $[10,74,75]$ (Table 2). In the largest cohort of participants examined, Phillips et al. [76] observed similar relative increases in $\mathrm{VO}_{2}$ peak in inactive men $(n=64)$ and women $(n=72)$ aged $18-50$ years in response to 6 weeks of thrice-weekly $5 \times 1 \mathrm{~min}$ at $\sim 125 \%$ $\mathrm{VO}_{2}$ peak. In addition, 6 weeks of the same protocol induced similar improvements in CRF in a smaller cohort of older (55-75 years) men and women [73]. Other shortterm interventions lasting 2-6 weeks have also observed no influence of sex on improvements in CRF among young men and women in response to various SIT protocols, including reduced volume SIT $(2-3 \times 20 \mathrm{~s}$ "allout" sprints $[53,69,71])$, Wingate-based SIT $(4-8 \times 30 \mathrm{~s}$ "all-out" sprints $[68,70])$ and Tabata-based SIT $(8 \times 20 \mathrm{~s}$ intervals at $\sim 170 \%$ peak power output, $10 \mathrm{~s}$ of recovery [72]).

While improvements in CRF are generally comparable between sexes, the relative contribution of central and peripheral mechanisms that underpin changes in $\mathrm{VO}_{2}$ peak with interval training may be influenced by sex. Exercise training-induced increases in $\mathrm{VO}_{2}$ peak are 


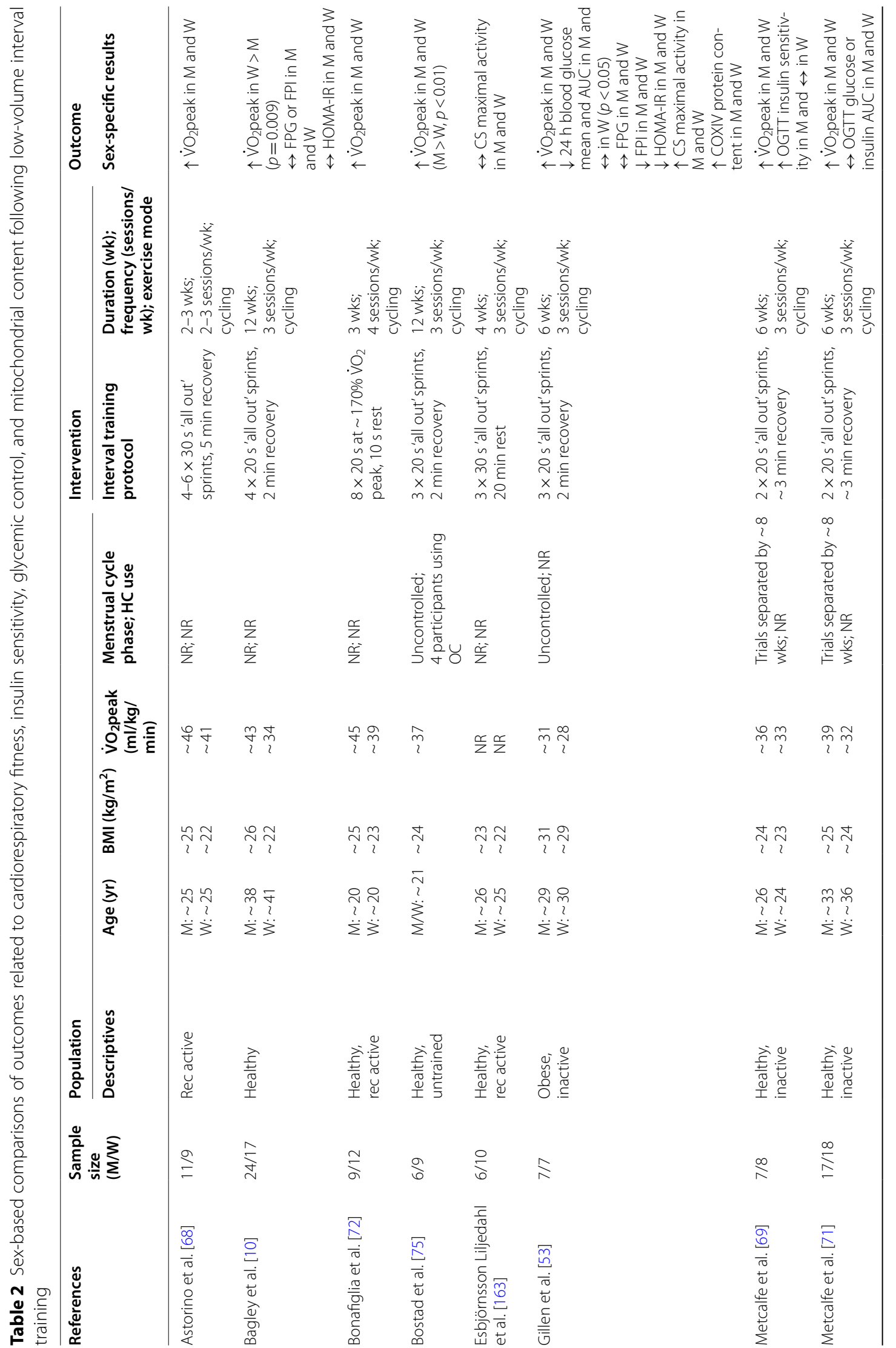




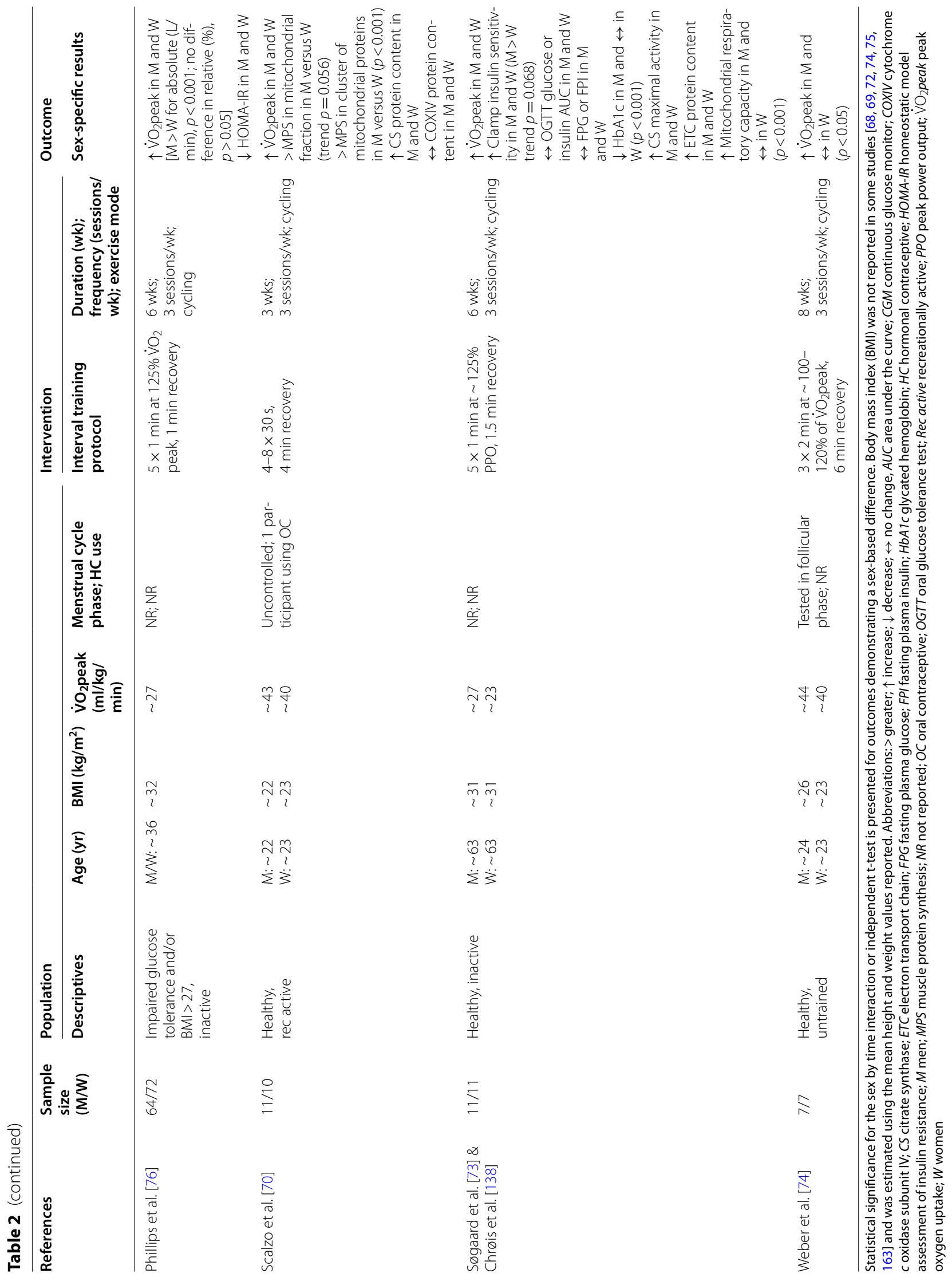


predominantly due to adaptations that increase oxygen transport, including peak cardiac output, blood volume and oxygen carrying capacity of the blood [77]. However, this knowledge is largely based on research conducted in men [77] and research examining central adaptations to low-volume interval training in women is scarce. Interestingly, an exploratory analysis in a recent study revealed a sex-specific peak cardiac output response to 6 and 12 weeks of SIT, involving thrice-weekly $3 \times 20 \mathrm{~s}$ sprints [75]. Despite improvements in CRF in both sexes, peak cardiac output was improved following training in inactive young men but was unchanged in women [75]. In contrast, Astorino et al. [78] reported no influence of sex on increases in peak cardiac output following $\sim 7$ weeks of different combinations of HIIT and/or SIT protocols that each involved a higher volume of work versus the $3 \times 20$ s SIT protocol examined by Bostad et al. [75]. The discrepancy between studies may be a result of small sample sizes and/or that neither study was primarily designed to assess sex-based differences in central responses to interval training. It is also possible that differences in participant characteristics such as ethnicity and oral contraceptive use could explain variability across studies, as both have been shown to modify peak cardiac output and stroke volume responses to low-volume interval training in women [46, 79]. Additional well-controlled sex-based comparisons of central and peripheral responses to low-volume interval training, and their contribution to improvements in CRF, is a fruitful area for future research.

\section{Insulin Sensitivity and Glycemic Control}

Exercise-induced improvements in insulin sensitivity and glycemic control contribute to the well-established benefits of exercise for the prevention and treatment of metabolic diseases. Low-volume interval training has been reported to improve fasting and peripheral estimates of insulin sensitivity and glycemic control in healthy adults and those with, or at risk for, cardiometabolic diseases [3]. However, determining whether sex modifies this health benefit of low-volume HIIT is important as a recent meta-analysis demonstrated that studies with a higher proportion of female participants are associated with smaller improvements in mean 24-h glucose following exercise [80]. Improvements in insulin sensitivity and glycemic control in response to weeks or months of exercise training are most commonly investigated, but acute improvements can also be observed for 24-48 h following a single session of exercise [81]. Thus, when considering the effects of low-volume interval training on insulin sensitivity and glycemic control in women, it is important to consider both acute and chronic responses.

\section{Acute Responses in Women and Sex-Based Comparisons}

The acute effects of low-volume interval training on insulin sensitivity and glycemic control are not well established in women, and available evidence in response to SIT as compared to HIT is conflicting. To the best of our knowledge, acute effects of low-volume SIT on estimates of insulin sensitivity or glycemic control have yet to be investigated in an independent cohort of women. However, in mixed cohorts of healthy young men and women, a single session of low-volume SIT, involving $4-6 \times 30$ s cycle sprints interspersed with 4 min of recovery, had no effect on insulin sensitivity measured via an oral glucose tolerance test (OGTT) [82] or hyperinsulinemic-euglycemic clamp [83] 14-16 h post-exercise. Similarly, unchanged OGTT-derived insulin sensitivity was also observed in response to a very low-volume SIT protocol involving $2 \times 20$ s cycle sprints within a 10 -min time commitment amongst a mixed-sex cohort of healthy young adults [84]. It is unclear if the lack of acute improvement in insulin sensitivity observed in mixed-sex cohorts is different from that which is observed in men alone, as there are reports of both improved intravenoustolerance test-derived insulin sensitivity in healthy men [85] and unchanged OGTT-derived insulin sensitivity in men with overweight [86], measured $\sim 24 \mathrm{~h}$ after a single session of low-volume SIT. Thus, while it is possible that the low exercise volume of SIT is insufficient to acutely improve insulin sensitivity independent of sex, comparisons between men and women are warranted in this regard.

Paradoxically, a single session of low-volume HIIT, involving $10 \times 1$ min cycling intervals at $90 \% \mathrm{HRmax}$, has been demonstrated to improve next-day fasting homeostasis model of insulin resistance (HOMA-IR) in women but not men [87]. HOMA-IR primarily reflects hepatic insulin sensitivity, and therefore, the sex-specific results may not be generalizable to estimates of peripheral insulin sensitivity obtained from methods such as OGTTs or hyperinsulinemic-euglycemic clamps. However, sexbased comparisons involving measurement of peripheral insulin sensitivity have not been conducted, and the efficacy of low-volume HIIT to improve peripheral insulin sensitivity and glycemic control in women can only be ascertained from mixed-sex cohorts. For example, using continuous glucose monitoring (CGM), improvements in indices of glycemic control have been reported following a single session of low-volume HIIT $(8-10 \times 1 \mathrm{~min}$ at 90\% HRmax) in mixed-sex cohorts with overweight/obesity $[88,89]$ and T2D [90]. The same low-volume HIIT protocol has also been demonstrated to improve insulin sensitivity, measured with the hyperinsulinemic-euglycemic clamp, 24 h following exercise in adults with overweight/obesity who have recently undergone a 12-week 
exercise-training program [91]. Some of these mixed-sex cohort studies have also directly compared the effects of acute low-volume HIIT to higher volumes of traditional MICT (40-45 min at $~ 70 \% \mathrm{HRmax}$ ), revealing no difference in the improvement in glycemic control [89] and insulin sensitivity [91], despite a reduced time commitment with HIIT. The potency of HIIT in this regard has been attributed to high rates of muscle glycogen utilization during exercise [91]. Considering there is evidence to suggest that muscle glycogen use during exercise is lower in women than men [92-94], and that exerciseinduced fuel metabolism is influenced by menstrual cycle phase and sex-hormone concentrations [95-98], sex-based comparisons and/or women-only studies may further enhance our understanding of the effect of lowvolume interval training on peripheral insulin sensitivity.

\section{Chronic Responses in Women and Sex-Based Comparisons:} Fasting Indices of Insulin Sensitivity and Glycemic Control

Fasting-derived estimates of insulin sensitivity and glycemic control have been widely reported following 6-15 weeks of low-volume interval training in womenonly cohorts. Trapp et al. [65] were amongst the first to demonstrate a reduction in fasting plasma insulin concentration measured $72 \mathrm{~h}$ following 15 weeks of lowvolume SIT in previously inactive but otherwise healthy women. The protocol involved $60 \times 8 \mathrm{~s}$ cycle sprints interspersed with $12 \mathrm{~s}$ recovery $(20 \mathrm{~min}$ total) and was found to elicit greater reductions in fasting insulin than a $40 \mathrm{~min}$ MICT protocol that was also performed three times per week for 15 weeks. More recently, Sun and colleagues [61] have used a similar low-volume SIT protocol in women with overweight and demonstrated greater reductions in HOMA-IR after 12 weeks of SIT than in response to a MICT protocol involving a threefold greater exercise volume. Encouraging findings in this regard have also been reported among women and girls across the lifespan who are understudied in exercise physiology. For example, HOMA-IR was reduced in adolescent girls with overweight and obesity following 12 weeks of running-based low-volume SIT (12$16 \times 30 \mathrm{~s}$ at maximal aerobic speed interspersed with $30 \mathrm{~s}$ recovery) performed twice a week [99]. In addition, the aforementioned 20-min low-volume SIT protocol, involving $60 \times 8 \mathrm{~s}$ cycle sprints interspersed with $12 \mathrm{~s}$ recovery, improved glycated hemoglobin (HbA1c) in postmenopausal women with T2D to a comparable extent as 40-min sessions of MICT at 60\% HRmax performed twice weekly for 16 weeks [100]. Women with polycystic ovary syndrome, a condition commonly associated with insulin resistance, have also been reported to improve HOMA-IR following 12 weeks of thrice-weekly aquatic-based low-volume HIIT [101]. Across these studies, training-induced improvements in insulin sensitivity and glycemic control have been largely attributed to concomitant reductions in total and/or abdominal body fat mass with training [61, 65, 99-101]. Available evidence also suggests that the improvement in HOMA-IR following 6 weeks of low-volume HIIT is similar between sexes [76].

\section{Chronic Responses in Women and Sex-Based Comparisons: Peripheral Indices of Insulin Sensitivity and Glycemic Control}

In contrast to fasting-derived indices of insulin sensitivity, estimates of peripheral insulin sensitivity are generally reported to be unchanged in women following low-volume interval training, which is different from findings in men. Two studies in full cohorts of women with overweight/obesity have observed no change in insulin sensitivity, assessed by OGTTs [50] or the hyperinsulinemic-euglycemic clamp [102], when measured $72 \mathrm{~h}$ following 6-14 weeks of low-volume HIIT. Metcalfe and colleagues [69] were the first to provide a direct sex comparison in this regard, demonstrating that after 6 weeks of low-volume SIT, involving thrice-weekly sessions of $2 \times 20$ s cycling sprints within a 10 -min time commitment, OGTT-derived insulin sensitivity was improved in healthy inactive men but not women. Gillen et al. [53] subsequently observed consistent sex differences amongst adults with overweight/obesity reporting that 6 weeks of a similar low-volume SIT protocol $(3 \times 20 \mathrm{~s}$ cycling sprints over $10 \mathrm{~min}$ performed three times per week) reduced 24-h blood glucose concentration in men but not women when measured 48-72 h after training using CGM. The authors also observed greater increases in skeletal muscle glucose transporter 4 (GLUT4) protein content in men [53], providing a potential mechanism for the sex difference in training-induced changes in glycemic control. More recently, Søgaard et al. [73] have measured sex-specific changes in insulin sensitivity, using the hyperinsulinemic-euglycemic clamp, following 6 weeks of interval training $\left(5 \times 1 \mathrm{~min}\right.$ at $\sim 125 \% \mathrm{VO}_{2}$ peak) performed three times per week in older adults. While a significant main effect of time was observed for the increase in glucose infusion rate during the clamp, the relative increase was $\sim 11 \%$ in men and $\sim 1 \%$ in women [73]. Collectively, available evidence suggests that women may 'respond less' than men with regard to low-volume interval training-induced improvements in peripheral insulin sensitivity and glycemic control.

It is important to mention that a number of studies involving mixed-sex cohorts have observed improvements in peripheral insulin sensitivity in healthy or overweight/obese adults following 2-12 weeks of lowvolume interval training $[83,91,103-105]$. There are also 
several mixed-sex studies in men and women with T2D that report improvements in glucose tolerance and glycemic control following 2-12 weeks of low-volume HIIT involving $10 \times 1$ min intervals at $~ 90 \%$ HRmax [106109]. Considering that these authors did not describe any sex differences when presenting the mixed-cohort results, it is possible that women do indeed improve indices of peripheral insulin sensitivity and glycemic control following low-volume interval training. In this case, it is possible that a lack of control for menstrual cycle phase in premenopausal women, not matching baseline insulin sensitivity in men and women, and/or differences in study design variables across studies, contribute to discrepancies within the literature and false conclusions regarding sex-based differences. Indeed, a more recent study from Metcalfe and colleagues [71] suggests that the previously reported differences between men and women might in fact be attributed to differences in baseline insulin sensitivity of participants, rather than sex, which corroborates other data suggesting that the degree of insulin resistance pre-training influences the adaptive response to HIIT [110]. Clearly, additional well-controlled sex-comparison studies are needed, including those that evaluate potential mechanisms.

Given the generally unchanged peripheral insulin sensitivity in women following low-volume interval training, it is possible that exercise protocols involving higher volumes of interval or continuous exercise are needed for more consistent improvements. Recently, a high volume HIIT protocol involving $1 \mathrm{~h}$ of cycling three times per week has been shown to improve insulin sensitivity, measured via the hyperinsulinemic-euglycemic clamp, in healthy premenopausal and early postmenopausal women after 12 weeks [111], perhaps suggesting a doseresponse threshold may exist. A training program that includes both high- and low-volume HIIT may also be an efficacious and (more) time-efficient option. Indeed, 2 weekly sessions of high-volume HIIT and 1 weekly session of low-volume HIIT ( $\sim 1.5 \mathrm{~h}$ per week) improved clamp-derived insulin sensitivity in young women after 10 weeks [112]. Continued research is needed to decipher the minimal exercise dose necessary to improve insulin sensitivity in women.

\section{Skeletal Muscle Mitochondrial Adaptations Responses in Women}

Exercise training-induced increases in skeletal muscle mitochondrial volume can enhance skeletal muscle oxidative capacity and thereby improve submaximal fuel metabolism, lactate threshold and ultimately endurance performance $[43,113]$. Another well-documented physiological adaptation to low-volume interval training is an increase in skeletal muscle mitochondrial content, as reviewed by others $[1,11]$. As little as 2 weeks of SIT or HIIT has been demonstrated to increase mitochondrial content in human skeletal muscle [114-118], which is most often assessed using biochemical measurements such as the maximal activity or protein content of mitochondrial enzymes including citrate synthase (CS), cytochrome $c$ oxidase subunit IV (COXIV) and succinate dehydrogenase $(\mathrm{SDH})[119,120]$. However, as recently acknowledged in a narrative review by Bishop and colleagues [11], this area of research is predominantly supported by studies conducted in men. Nonetheless, there is evidence from a limited number of women-only cohorts demonstrating HIIT-induced improvements in biomarkers of mitochondrial content. To our knowledge, Gillen et al. [50] were the first to demonstrate increased skeletal muscle mitochondrial content following low-volume HIIT in an independent cohort of women. Following 6 weeks of thrice-weekly exercise, involving $10 \times 1 \mathrm{~min}$ cycling intervals at $90 \% \mathrm{HRmax}$, the maximal activity of CS was increased in young women with overweight or obesity. A companion paper from the same cohort [121] further demonstrated increases in COXIV activity in type 1 and 2 muscle fibers using immunofluorescence. While the results from this intervention $[50,121]$ reveal that 6 weeks of low-volume HIIT increases mitochondrial content in women with overweight or obesity, it provides limited insight compared to the wealth of low-volume HIIT/SIT studies conducted in men-only cohorts that vary in training protocol (e.g., [117, 122-124]), training duration (e.g., $[118,125,126])$, and participant characteristics (e.g., [127-129]).

A few studies using high-volume HIIT protocols ( $\geq 60 \mathrm{~min}$ per session) have revealed increased mitochondrial content in a range of women-only cohorts following 2-12 weeks of training. For example, increased maximal activity of CS was observed in young healthy women following 2 or 6 weeks of three weekly sessions involving $10 \times 4$ min cycling efforts at $90 \% \dot{\mathrm{VO}}_{2}$ peak, interspersed with $2 \mathrm{~min}$ of rest [130,131]. More recently, Nyberg and colleagues [132] have demonstrated 12 weeks of interval training (1-h cycling classes involving highintensity intervals), three times per week, increased mitochondrial protein content in pre- and postmenopausal women. Notably, the improvements following training were more pronounced in postmenopausal women compared to premenopausal women, suggesting that menopausal status may impact mitochondrial responses to interval training. Future work should explore the influence of menopausal status on mitochondrial responses to low-volume interval training. 
Low-Volume Interval Training Versus MICT

Given the limited number of low-volume HIIT or SIT studies conducted in women, it is perhaps unsurprising that we know relatively little with regard to how mitochondrial adaptations in response to low-volume interval training compare to traditional forms of aerobic training (e.g., high-volume MICT) in women. When considering mixed-sex cohorts, however, similar improvements in mitochondrial content have been observed following 6 weeks of low-volume SIT and MICT in young healthy men and women. Specifically, Burgomaster et al. [133] observed similar increases in the maximal activity of CS between these protocols despite a $\sim 3$-fold lower time commitment and $\sim 10$-fold lower exercise volume with SIT (4-6 $\times 30 \mathrm{~s}$ "all-out" cycling sprints), as compared to MICT (40-60 min cycling at $65 \% \mathrm{VO}_{2}$ peak). This finding is consistent with recent studies demonstrating no difference in training-induced improvements in biomarkers of mitochondrial content or total mitochondrial volume following 6-12 weeks of low-volume HIIT and MICT in adults with overweight or obesity $[91,105,134]$ or T2D [135]. Thus, based on these mixed-sex studies it is plausible that low-volume interval training and MICT similarly increase mitochondrial content in women, consistent with several studies in men-only cohorts $[116,125,136$, 137]; however, this notion has not been examined in an independent cohort of women.

\section{Sex-Based Comparisons}

The importance of investigating mitochondrial adaptations in women-only cohorts is bolstered by recent evidence demonstrating sex-based differences in the adaptive response to low-volume interval training. Three weeks of low-volume SIT, consisting of $4-8 \times 30 \mathrm{~s}$ Wingate sprints with 4 min of active recovery performed 3 times per week, induced greater rates of mitochondrial biogenesis in young healthy men relative to women, as evidenced by greater synthesis of mitochondrial proteins, when analyzed as a cluster, and a tendency for higher rates of protein synthesis in the mitochondrial fraction in men [70]. A sex-specific response to low-volume interval training was also observed in a recent study by Chrøis et al. [138], whereby older men but not women ( 63 years) increased mitochondrial respiration following 6 weeks of $5 \times 1$ min intervals at $\sim 125 \% \mathrm{VO}_{2}$ peak. The mechanistic basis for the reported greater mitochondrial responses in men compared to women remains unclear. Interval training-induced mitochondrial biogenesis is initiated by repeated, transient disturbances in metabolic homeostasis that activate signaling pathways which promote the transcription of genes and translation of mitochondrial proteins $[1,139]$. This knowledge, however, is largely based on data in men, and there is a dearth of research that has examined acute responses involved in mitochondrial biogenesis such as the phosphorylation of AMP-activated protein kinase (AMPK) or mRNA expression of peroxisome proliferator activated receptor gamma coactivator $1 a(\mathrm{PGC} 1 \alpha)$ in women. Recent efforts have attempted to compare responses between men and women in this regard, but no sex difference has been observed in the phosphorylation of AMPK [140] or PGC1 $\alpha$ mRNA expression [141] following a single session of low-volume HIIT $\left(6 \times 1.5 \mathrm{~min}\right.$ at $90 \% \mathrm{VO}_{2}$ peak; [140]) or SIT $(3 \times 20 \mathrm{~s}$ "all-out" sprints; [141]). Additional work that examines acute molecular responses to lowvolume interval training in women of varying age and health status, including sex-based comparisons, may provide insight into the observed greater rates of mitochondrial biogenesis [70] and improvements in mitochondrial respiration [138] in men relative to women.

There is also evidence that low-volume interval training elicits comparable mitochondrial adaptations between sexes, specifically with respect to biomarkers of mitochondrial content. Training-induced increases in the maximal activity or protein content of CS following 3 or 6 weeks of low-volume SIT did not differ between men and women who were recreationally active [70], inactive with overweight or obesity [53] or inactive and older [138]. The similar net change in mitochondrial content, despite the aforementioned tendency for greater rates of mitochondrial protein synthesis in men [70], may be explained by higher rates of mitochondrial protein breakdown in men compared with women. It is also possible that the small sample sizes of men and women $(n \leq 11$ each) examined in these investigations were underpowered to detect differences in interval training-induced improvements in mitochondrial content between sexes. Future research in larger sample sizes that examines a comprehensive set of mitochondrial measures (i.e., mitochondrial protein synthesis, content and function) is required to clarify mitochondrial adaptations to lowvolume interval training in women relative to men. This work should also include sex-based comparisons using different HIIT protocols, since the research in this area has primarily utilized interval training protocols involving only very brief amounts of intense exercise ( $\leq 5 \mathrm{~min})$.

\section{Methodological Considerations and Directions for Future Research}

Reasons for the lower representation of women as participants in exercise research studies [14-16] are numerous and complex and may include investigator-driven decisions and sex-based differences in willingness to participate [142, 143]. Regardless, more research in women is needed that evaluates the impact of population characteristics (e.g., age, presence of chronic disease, menopausal 
status), methodology utilized to assess outcomes (e.g., type of graded exercise test protocol to determine CRF), and intervention variables (e.g., length of training period, variations in the interval exercise protocol, progression of training load) on physiological responses to low-volume interval training, as these factors may have influenced the conclusions discussed herein. Progress in this regard will require targeted recruitment strategies and careful consideration of women-specific methodological factors in study design. For example, in premenopausal women, menstrual cycle phase has been demonstrated to influence resting insulin sensitivity [144] and exerciseinduced mitochondrial gene expression [145]. Oral contraceptives, taken by $\sim 151$ million women worldwide in 2019 [146], add further complexity as they have been reported to blunt increases in CRF and maximal cardiac output following 4 weeks of low-volume interval training [79]. Thus, careful consideration of these factors is necessary for the proper design of future studies that include women as participants, and recommendations in this regard have recently been made by others [147149]. While controlling for menstrual cycle phase and hormonal contraceptive use are generally recommended and would improve the quality of women-specific data, this approach may also introduce limitations such as decreased generalizability of the results and increased timescale [149]. Thus, methodological decisions in this regard should be carefully considered for each study and guided by the specific research question. Nonetheless, enhanced documentation and reporting of hormonal parameter(s), using consistent definitions, as provided by others [149], are needed to reduce ambiguity and help clarify conflicting findings between studies.

Properly matching both participant characteristics and the exercise stimulus remains a challenging issue for sex-based comparison studies. There is evidence of greater baseline insulin sensitivity [150] and mitochondrial volume [151] in women relative to men, which may impact training-induced responses. It is also well known that $\mathrm{VO}_{2}$ peak relative to body mass is lower in women compared to men of a similar training background [152-154]. Given this sex-based difference, and the greater body fat percentage in women compared with men, it has been suggested to match men and women for fitness levels using $\mathrm{VO}_{2}$ peak relative to fat free mass [155]. The optimal method for matching the interval exercise stimulus in sex-comparison studies, however, is an unresolved issue, as noted by Bishop and colleagues [11]. Men typically produce larger power outputs during "all-out" SIT protocols compared with women [70, 93] and a discrepancy in work performed during interval training may contribute to the observed greater responses in men. Some authors have compared power outputs during SIT relative to whole body fatfree mass to account for sex-based differences in body composition and found no sex differences in relative power output [53, 70, 93, 141]. However, this outcome may need to be interpreted with caution since cycling is a lower body exercise and there may be sex differences in the relative contribution of lower body fat free mass to total fat free mass [156]. Moreover, there is large between-participant variability in the homeostatic disturbance elicited by reference points commonly used to determine exercise intensity in interval training protocols [e.g., HRmax, $\mathrm{VO}_{2}$ peak or peak power output (Wpeak)] [11, 157], which can confound sex-based comparisons. As such, it has been suggested that prescribing exercise intensity relative to metabolic thresholds may be more appropriate for sex-based comparisons [17]. The methodological decisions related to matching the interval exercise stimulus between men and women may also depend on the study objective(s) and whether the findings will address a more applied or basic science research question.

Given the evidence that women may "respond less" to interval training, it is important for future work to assess whether modifications to the interval training stimulus can augment responses in women. Manipulation of the interval exercise prescription variables (e.g., exercise intensity, duration, work to recovery ratio) and/or periexercise nutrition represent strategies in this regard. For example, women have been reported to have faster metabolic recovery following repeated Wingate sprints relative to men $[93,158]$ and therefore may require shorter recovery periods between high-intensity intervals [17]. Indeed, a recent study by Schmitz and colleagues found that 4 weeks of SIT involving shorter $(30 \mathrm{~s})$ rather than longer (180 s) active recovery periods improved repeated running ability in women [159]. Whether altering the recovery duration during low-volume interval training modifies improvements in CRF, insulin sensitivity and mitochondrial content in women remains largely unexplored. Nutrition and/or ergogenic aids may also augment physiological adaptations to low-volume interval training in women, and investigations examining sexspecific nutritional strategies for interval training are needed. Interestingly, when 8 weeks of low-volume HIIT was combined with caffeine supplementation in women with obesity, larger improvements in glycemic control during an OGTT were observed compared to those who underwent training without caffeine supplementation [160]. Additional research that examines the potential for nutrition to modify chronic responses to low-volume interval training in women would advance the field further. Studies that assess the mechanisms by which low-volume interval training improves physiological 
responses in women are also warranted and will provide insight into how to optimize the interval exercise stimulus for women.

\section{Conclusion}

There is a relative lack of data regarding physiological responses to low-volume interval training in women as compared to men. Nonetheless, given the wealth of research conducted over the past two decades, the efficacy of low-volume HIIT and SIT to improve select outcome variables in women, such as CRF, has been consistently demonstrated. However, research that explores peripheral adaptations to low-volume interval training in women-only cohorts, such as skeletal muscle mitochondrial responses and insulin sensitivity, is limited and conflicting, with some evidence demonstrating blunted improvements in women relative to men. Further research is needed to clarify and advance our knowledge of these interval training-induced responses in women of various ages, activity levels and health statuses, including studies that provide direct comparisons to traditional MICT. Additional sexcomparison studies that utilize best practice guidelines for matching men and women are also needed, as are studies that evaluate a mechanistic basis for previously reported sex-specific adaptations to low-volume interval training. To increase our understanding of physiological adaptations to low-volume interval training in women, it is also necessary to evaluate the influence of training variables (e.g., training duration, protocol, exercise modality), and possible ergogenic or ergolytic variables (e.g., peri-exercise nutrition, supplements, hormonal contraceptives) on HIIT/SIT responses in women-only cohorts across the lifespan. These research efforts are important and necessary from both a basic science and translational perspective, and will support sex and gender equity in research while strengthening the evidence-base for physical activity recommendations in women.

\section{Authors' Contributions}

LES and JBG conceived the article. All authors contributed to the literature search and the original manuscript draft. All authors read and approved the final manuscript.

\section{Funding}

No funding was received to prepare this manuscript. Lauren E. Skelly was supported by a Canadian Institutes of Health Research Postdoctoral Fellowship (\#164711). Jenna B. Gillen is supported by the Natural Sciences and Engineering Research Council of Canada (RGPIN-2020-05779).

\section{Availability of Data and Materials}

Not applicable.

\section{Code Availability}

Not applicable.

\section{Declarations}

Ethics Approval and Consent to Participate

Not applicable.

\section{Consent for Publication}

Not applicable.

\section{Competing interests}

Lauren E. Skelly, Celine Bailleul and Jenna B. Gillen declare no conflict of interest.

\section{Author details \\ ${ }^{1}$ School of Kinesiology and Health Science, Faculty of Health, York University, Toronto, ON, Canada. ${ }^{2}$ Faculty of Kinesiology and Physical Education, Univer- sity of Toronto, Toronto, ON, Canada.}

Received: 9 September 2021 Accepted: 26 November 2021

Published online: 23 December 2021

\section{References}

1. Maclnnis MJ, Gibala MJ. Physiological adaptations to interval training and the role of exercise intensity. J Physiol. 2017;595(9):2915-30. https://doi.org/10.1113/JP273196.

2. Batacan RB Jr, Duncan MJ, Dalbo VJ, Tucker PS, Fenning AS. Effects of high-intensity interval training on cardiometabolic health: a systematic review and meta-analysis of intervention studies. $\mathrm{Br} J$ Sports Med. 2017:51(6):494-503. https://doi.org/10.1136/bjsports-2015-095841.

3. Jelleyman C, Yates T, O'Donovan G, Gray LJ, King JA, Khunti K, et al. The effects of high-intensity interval training on glucose regulation and insulin resistance: a meta-analysis. Obes Rev. 2015;16(11):942-61. https://doi.org/10.1111/obr.12317.

4. Campbell WW, Kraus WE, Powell KE, Haskell WL, Janz KF, Jakicic JM, et al. High-intensity interval training for cardiometabolic disease prevention. Med Sci Sports Exerc. 2019;51(6):1220-6. https://doi.org/10.1249/MSS. 0000000000001934

5. Sabag A, Little JP, Johnson NA. Low-volume high-intensity interval training for cardiometabolic health. J Physiol. 2021. https://doi.org/10.1113/ JP281210.

6. Colberg SR, Sigal RJ, Yardley JE, Riddell MC, Dunstan DW, Dempsey PC, et al. Physical activity/exercise and diabetes: a position statement of the American Diabetes Association. Diabetes Care. 2016;39(11):2065-79. https://doi.org/10.2337/dc16-1728.

7. Department of Health and Social Care. UK Chief Medical Officers' Physical Activity Guidelines. United Kingdom (2019).

8. Thompson WR. Worldwide survey of fitness trends for 2021. ACSM'S Health Fitness J. 2021;25(1):10-9. https://doi.org/10.1249/FIT.00000 00000000631.

9. Trost SG, Owen N, Bauman AE, Sallis JF, Brown W. Correlates of adults' participation in physical activity: review and update. Med Sci Sports Exerc. 2002;34(12):1996-2001. https://doi.org/10.1249/01.MSS.00000 38974.76900.92.

10. Bagley L, Slevin M, Bradburn S, Liu D, Murgatroyd C, Morrissey G, et al. Sex differences in the effects of 12 weeks sprint interval training on body fat mass and the rates of fatty acid oxidation and $\mathrm{VO}_{2}$ max during exercise. BMJ Open Sport Exerc Med. 2016;2(1): e000056. https://doi. org/10.1136/bmjsem-2015-000056.

11. Bishop DJ, Botella J, Genders AJ, Lee MJ, Saner NJ, Kuang J, et al. Highintensity exercise and mitochondrial biogenesis: current controversies and future research directions. Physiology (Bethesda). 2019;34(1):56-70. https://doi.org/10.1152/physiol.00038.2018.

12. Way KL, Vidal-Almela S, Moholdt T, Currie KD, Aksetoy IA, Boidin M, et al. Sex differences in cardiometabolic health indicators following HIIT in patients with coronary artery disease. Med Sci Sports Exerc. 2021;53(7):1345-55. https://doi.org/10.1249/MSS.0000000000002596.

13. Atakan MM, Li Y, Kosar SN, Turnagol HH, Yan X. Evidence-based effects of high-intensity interval training on exercise capacity and health: 
a review with historical perspective. Int J Environ Res Public Health. 2021;18(13):7201. https://doi.org/10.3390/ijerph18137201.

14. O'Halloran KD. Mind the gap: widening the demographic to establish new norms in human physiology. J Physiol. 2020;598(15):3045-7. https://doi.org/10.1113/JP279986.

15. Costello JT, Bieuzen F, Bleakley CM. Where are all the female participants in Sports and Exercise Medicine research? Eur J Sport Sci. 2014;14(8):847-51. https://doi.org/10.1080/17461391.2014.911354.

16. Devries MC, Jakobi JM. Importance of considering sex and gender in exercise and nutrition research. Appl Physiol Nutr Metab. 2021;46(6):iiivii. https://doi.org/10.1139/apnm-2021-0298.

17. Ansdell P, Thomas K, Hicks KM, Hunter SK, Howatson G, Goodall S. Physiological sex differences affect the integrative response to exercise: acute and chronic implications. Exp Physiol. 2020;105(12):2007-21. https://doi.org/10.1113/EP088548.

18. Devries MC. Sex-based differences in endurance exercise muscle metabolism: impact on exercise and nutritional strategies to optimize health and performance in women. Exp Physiol. 2016;101 (2):243-9. https://doi.org/10.1113/EP085369.

19. Wohlgemuth KJ, Arieta LR, Brewer GJ, Hoselton AL, Gould LM, SmithRyan AE. Sex differences and considerations for female specific nutritional strategies: a narrative review. J Int Soc Sports Nutr. 2021;18(1):27. https://doi.org/10.1186/s12970-021-00422-8.

20. Brockman N, Yardley J. Sex-related differences in fuel utilization and hormonal response to exercise: implications for individuals with type 1 diabetes. Appl Physiol Nutr Metab. 2017;43(6):541-52. https://doi.org/ 10.1139/apnm-2017-0559.

21. Dominelli PB, Molgat-Seon Y, Sheel AW. Sex differences in the pulmonary system influence the integrative response to exercise. Exerc Sport Sci Rev. 2019;47(3):142-50. https://doi.org/10.1249/JES.0000000000 000188

22. Tiller NB, Elliott-Sale KJ, Knechtle B, Wilson PB, Roberts JD, Millet GY. Do sex differences in physiology confer a female advantage in ultra-endurance sport? Sports Med. 2021;51(5):895-915. https://doi.org/10.1007/ s40279-020-01417-2.

23. Williams JS, Dunford EC, Cheng JL, Moncion K, Valentino SE, Droog $C A$, et al. The impact of the $24-h$ movement spectrum on vascular remodeling in older men and women: a review. Am J Physiol Heart Circ Physiol. 2021;320(3):H1136-55. https://doi.org/10.1152/ajpheart.00754. 2020.

24. Forbes SC, Candow DG, Smith-Ryan AE, Hirsch KR, Roberts MD, VanDusseldorp TA, et al. Supplements and nutritional interventions to augment high-intensity interval training physiological and performance adaptations-a narrative review. Nutrients. 2020;12(2):390. https://doi. org/10.3390/nu12020390

25. Gibala MJ, Little JP. Physiological basis of brief vigorous exercise to improve health. J Physiol. 2020;598(1):61-9. https://doi.org/10.1113/ JP276849.

26. Weston KS, Wisloff $\mathrm{U}$, Coombes JS. High-intensity interval training in patients with lifestyle-induced cardiometabolic disease: a systematic review and meta-analysis. Br J Sports Med. 2014;48(16):1227-34 https://doi.org/10.1136/bjsports-2013-092576.

27. Taylor JL, Holland DJ, Spathis JG, Beetham KS, Wisloff U, Keating SE, et al. Guidelines for the delivery and monitoring of high intensity interval training in clinical populations. Prog Cardiovasc Dis. 2019;62(2):140-6. https://doi.org/10.1016/j.pcad.2019.01.004.

28. Gist NH, Fedewa MV, Dishman RK, Cureton KJ. Sprint interval training effects on aerobic capacity: a systematic review and metaanalysis. Sports Med. 2014;44(2):269-79. https://doi.org/10.1007/ s40279-013-0115-0.

29. Bacon AP, Carter RE, Ogle EA, Joyner MJ. VO2max trainability and high intensity interval training in humans: a meta-analysis. PLOS ONE. 2013;8(9): e73182. https://doi.org/10.1371/journal.pone.0073182.

30. Bouaziz W, Malgoyre A, Schmitt E, Lang PO, Vogel T, Kanagaratnam L. Effect of high-intensity interval training and continuous endurance training on peak oxygen uptake among seniors aged 65 or older: a meta-analysis of randomized controlled trials. Int J Clin Pract. 2020;74(6): e13490. https://doi.org/10.1111/ijcp.13490.

31. Sant'Ana LO, Machado S, Ribeiro AAS, Dos Reis NR, Campos YAC, da Silva JGV, et al. Effects of cardiovascular interval training in healthy elderly subjects: a systematic review. Front Physiol. 2020;11:739. https:// doi.org/10.3389/fphys.2020.00739.

32. Milanovic Z, Sporis G, Weston M. Effectiveness of High-Intensity Interval Training (HIT) and continuous endurance training for VO2max improvements: a systematic review and meta-analysis of controlled trials. Sports Med. 2015;45(10):1469-81. https://doi.org/10.1007/s40279-015-0365-0.

33. Sloth M, Sloth D, Overgaard K, Dalgas U. Effects of sprint interval training on VO2max and aerobic exercise performance: a systematic review and meta-analysis. Scand J Med Sci Sports. 2013;23(6):e341-52. https:// doi.org/10.1111/sms.12092.

34. Vollaard NBJ, Metcalfe RS, Williams S. Effect of number of sprints in an SIT session on change in V O2max: a meta-analysis. Med Sci Sports Exerc. 2017;49(6):1147-56. https://doi.org/10.1249/MSS.0000000000 001204.

35. Su L, Fu J, Sun S, Zhao G, Cheng W, Dou C, et al. Effects of HIIT and MICT on cardiovascular risk factors in adults with overweight and/or obesity: A meta-analysis. PLoS ONE. 2019;14(1): e0210644. https://doi.org/10. 1371/journal.pone.0210644.

36. Sultana RN, Sabag A, Keating SE, Johnson NA. The effect of low-volume high-intensity interval training on body composition and cardiorespiratory fitness: a systematic review and meta-analysis. Sports Med. 2019:49(11):1687-721. https://doi.org/10.1007/s40279-019-01167-w.

37. Lora-Pozo I, Lucena-Anton D, Salazar A, Galan-Mercant A, Moral-Munoz JA. Anthropometric, cardiopulmonary and metabolic benefits of the high-intensity interval training versus moderate, low-intensity or control for type 2 diabetes: systematic review and meta-analysis. Int J Environ Res Public Health. 2019:16(22):4524. https://doi.org/10.3390/ ijerph16224524.

38. Liu JX, Zhu L, Li PJ, Li N, Xu YB. Effectiveness of high-intensity interval training on glycemic control and cardiorespiratory fitness in patients with type 2 diabetes: a systematic review and meta-analysis. Aging Clin Exp Res. 2019;31 (5):575-93. https://doi.org/10.1007/s40520-018-1012-z.

39. Qiu S, Cai X, Sun Z, Zugel M, Steinacker JM, Schumann U. Aerobic interval training and cardiometabolic health in patients with type 2 diabetes: a meta-analysis. Front Physiol. 2017;8:957. https://doi.org/10 3389/fphys.2017.00957.

40. Weston M, Taylor KL, Batterham AM, Hopkins WG. Effects of low-volume high-intensity interval training (HIT) on fitness in adults: a meta-analysis of controlled and non-controlled trials. Sports Med. 2014;44(7):1005-17. https://doi.org/10.1007/s40279-014-0180-z.

41. Ross R, Blair SN, Arena R, Church TS, Despres JP, Franklin BA, et al. Importance of assessing cardiorespiratory fitness in clinical practice: a case for fitness as a clinical vital sign: a scientific statement from the American Heart Association. Circulation. 2016;134(24):e653-99. https://doi.org/10. 1161/CIR.0000000000000461.

42. Kodama S, Saito K, Tanaka S, Maki M, Yachi Y, Asumi M, et al. Cardiorespiratory fitness as a quantitative predictor of all-cause mortality and cardiovascular events in healthy men and women: a meta-analysis. JAMA. 2009:301(19):2024-35. https://doi.org/10.1001/jama.2009.681.

43. Joyner MJ, Coyle EF. Endurance exercise performance: the physiology of champions. J Physiol. 2008;586(1):35-44. https://doi.org/10.1113/jphys iol.2007.143834

44. Trilk JL, Singhal A, Bigelman KA, Cureton KJ. Effect of sprint interval training on circulatory function during exercise in sedentary, overweight/obese women. Eur J Appl Physiol. 2011;111(8):1591-7. https:// doi.org/10.1007/s00421-010-1777-z.

45. Walter AA, Smith AE, Kendall KL, Stout JR, Cramer JT. Six weeks of highintensity interval training with and without beta-alanine supplementation for improving cardiovascular fitness in women. J Strength Cond Res. 2010;24(5):1199-207. https://doi.org/10.1519/JSC.0b013e3181 d82f8b.

46. De Revere $\mathrm{JL}$, Clausen RD, Astorino TA. Changes in VO2max and cardiac output in response to short-term high-intensity interval training in Caucasian and Hispanic young women: a pilot study. PLoS ONE. 2021;16(1): e0244850. https://doi.org/10.1371/journal.pone.0244850.

47. Naves JPA, Viana RB, Rebelo ACS, de Lira CAB, Pimentel GD, Lobo PCB, et al. Effects of high-intensity interval training vs. sprint interval training on anthropometric measures and cardiorespiratory fitness in healthy young women. Front Physiol. 2018;9:1738. https://doi.org/10.3389/ fphys.2018.01738. 
48. Forbes SC, Sletten N, Durrer C, Myette-Cote E, Candow D, Little JP. Creatine monohydrate supplementation does not augment fitness, performance, or body composition adaptations in response to four weeks of high-intensity interval training in young females. Int J Sport Nutr Exerc Metab. 2017;27(3):285-92. https://doi.org/10.1123/ijsnem. 2016-0129.

49. Astorino TA, Schubert MM, Palumbo E, Stirling D, McMillan DW, Cooper $C$, et al. Magnitude and time course of changes in maximal oxygen uptake in response to distinct regimens of chronic interval training in sedentary women. Eur J Appl Physiol. 2013;113(9):2361-9. https://doi. org/10.1007/s00421-013-2672-1.

50. Gillen JB, Percival ME, Ludzki A, Tarnopolsky MA, Gibala MJ. Interval training in the fed or fasted state improves body composition and muscle oxidative capacity in overweight women. Obesity (Silver Spring). 2013;21(11):2249-55. https://doi.org/10.1002/oby.20379.

51. Boutcher SH, Park Y, Dunn SL, Boutcher YN. The relationship between cardiac autonomic function and maximal oxygen uptake response to high-intensity intermittent-exercise training. J Sports Sci. 2013;31(9):1024-9. https://doi.org/10.1080/02640414.2012.762984.

52. Allison MK, Baglole JH, Martin BJ, Macinnis MJ, Gurd BJ, Gibala MJ. Brief intense stair climbing improves cardiorespiratory fitness. Med Sci Sports Exerc. 2017;49(2):298-307. https://doi.org/10.1249/MSS.00000 00000001188

53. Gillen JB, Percival ME, Skelly LE, Martin BJ, Tan RB, Tarnopolsky MA, et al. Three minutes of all-out intermittent exercise per week increases skeletal muscle oxidative capacity and improves cardiometabolic health. PLoS ONE. 2014;9(11): e111489. https://doi.org/10.1371/journal.pone. 0111489.

54. Hazell TJ, Hamilton CD, Olver TD, Lemon PW. Running sprint interval training induces fat loss in women. Appl Physiol Nutr Metab. 2014;39(8):944-50. https://doi.org/10.1139/apnm-2013-0503.

55. Rowley TW, Espinoza JL, Akers JD, Wenos DL, Edwards ES, Couillard C. Effects of run sprint interval training on healthy, inactive, overweight/ obese women: a pilot study. Facets. 2017;2(1):53-67. https://doi.org/10. 1139/facets-2016-0004

56. Marcotte-Chenard A, Tremblay D, Mony MM, Brochu M, Dionne IJ, Langlois MF, et al. Low-volume walking HIIT: Efficient strategy to improve physical capacity and reduce the risk of cardiovascular disease in older women with type 2 diabetes. Diabetes Metab Syndr. 2021;15(5):102233. https://doi.org/10.1016/j.dsx.2021.102233.

57. Boukabous I, Marcotte-Chenard A, Amamou T, Boulay P, Brochu M, Tessier D, et al. Low-volume High-Intensity Interval Training (HIIT) versus moderate-intensity continuous training on body composition, cardiometabolic profile and physical capacity in older women. J Aging Phys Act. 2019;27(4):879-89. https://doi.org/10.1123/japa.2018-0309.

58. Lionett S, Kiel IA, Camera DM, Vanky E, Parr EB, Lydersen S, et al. Circulating and adipose tissue miRNAs in women with polycystic ovary syndrome and responses to high-intensity interval training. Front Physiol. 2020;11:904. https://doi.org/10.3389/fphys.2020.00904.

59. Bonafiglia JT, Islam H, Preobrazenski N, Gurd BJ. Risk of bias and reporting practices in studies comparing $\mathrm{VO} 2$ max responses to sprint interval vs. continuous training: a systematic review and meta-analysis. J Sport Health Sci. 2021. https://doi.org/10.1016/j.jshs.2021.03.005.

60. Kong Z, Fan X, Sun S, Song L, Shi Q, Nie J. Comparison of high-intensity interval training and moderate-to-vigorous continuous training for cardiometabolic health and exercise enjoyment in obese young women: a randomized controlled trial. PLOS ONE. 2016;11(7):e0158589. https:// doi.org/10.1371/journal.pone.0158589.

61. Sun S, Zhang H, Kong Z, Shi Q, Tong TK, Nie J. Twelve weeks of low volume sprint interval training improves cardio-metabolic health outcomes in overweight females. J Sports Sci. 2019;37(11):1257-64. https://doi.org/10.1080/02640414.2018.1554615.

62. Sun S, Kong Z, Shi Q, Hu M, Zhang H, Zhang D, et al. Non-energyrestricted low-carbohydrate diet combined with exercise intervention improved cardiometabolic health in overweight Chinese females. Nutrients. 2019;11(12):3051. https://doi.org/10.3390/nu11123051.

63. Hu M, Kong Z, Sun S, Zou L, Shi Q, Chow BC, et al. Interval training causes the same exercise enjoyment as moderate-intensity training to improve cardiorespiratory fitness and body composition in young Chinese women with elevated BMI. J Sports Sci. 2021;39(15):1677-86. https://doi.org/10.1080/02640414.2021.1892946.
64. Klonizakis M, Moss J, Gilbert S, Broom D, Foster J, Tew GA. Low-volume high-intensity interval training rapidly improves cardiopulmonary function in postmenopausal women. Menopause. 2014;21(10):1099-105. https://doi.org/10.1097/GME.0000000000000208.

65. Trapp EG, Chisholm DJ, Freund J, Boutcher SH. The effects of high-intensity intermittent exercise training on fat loss and fasting insulin levels of young women. Int J Obes (Lond). 2008;32(4):684-91. https://doi.org/10. 1038/sj.ijo.0803781.

66. Dupuit M, Rance M, Morel C, Bouillon P, Pereira B, Bonnet A, et al. Moderate-intensity continuous training or high-intensity interval training with or without resistance training for altering body composition in postmenopausal women. Med Sci Sports Exerc. 2020;52(3):736-45. https://doi.org/10.1249/MSS.0000000000002162.

67. Higgins S, Fedewa MV, Hathaway ED, Schmidt MD, Evans EM. Sprint interval and moderate-intensity cycling training differentially affect adiposity and aerobic capacity in overweight young-adult women. Appl Physiol Nutr Metab. 2016;41(11):1177-83. https://doi.org/10.1139/ apnm-2016-0240.

68. Astorino TA, Allen RP, Roberson DW, Jurancich M, Lewis R, McCarthy K, et al. Adaptations to high-intensity training are independent of gender. Eur J Appl Physiol. 2011;111(7):1279-86. https://doi.org/10.1007/ s00421-010-1741-y.

69. Metcalfe RS, Babraj JA, Fawkner SG, Vollaard NB. Towards the minimal amount of exercise for improving metabolic health: beneficial effects of reduced-exertion high-intensity interval training. Eur J Appl Physiol. 2012;112(7):2767-75. https://doi.org/10.1007/s00421-011-2254-z.

70. Scalzo RL, Peltonen GL, Binns SE, Shankaran M, Giordano GR, Hartley $D A$, et al. Greater muscle protein synthesis and mitochondrial biogenesis in males compared with females during sprint interval training. FASEB J. 2014;28(6):2705-14. https://doi.org/10.1096/f.13-246595.

71. Metcalfe RS, Tardif N, Thompson D, Vollaard NB. Changes in aerobic capacity and glycaemic control in response to reduced-exertion highintensity interval training (REHIT) are not different between sedentary men and women. Appl Physiol Nutr Metab. 2016;41(11):1117-23. https://doi.org/10.1139/apnm-2016-0253.

72. Bonafiglia JT, Rotundo MP, Whittall JP, Scribbans TD, Graham RB, Gurd BJ. Inter-individual variability in the adaptive responses to endurance and sprint interval training: a randomized crossover study. PLoS ONE. 2016;11(12):e0167790. https://doi.org/10.1371/journal.pone.0167790.

73. Sogaard D, Lund MT, Scheuer CM, Dehlbaek MS, Dideriksen SG, Abildskov CV, et al. High-intensity interval training improves insulin sensitivity in older individuals. Acta Physiol (Oxf). 2018;222(4):e13009. https:// doi.org/10.1111/apha.13009.

74. Weber CL, Schneider DA. Increases in maximal accumulated oxygen deficit after high-intensity interval training are not gender dependent. J Appl Physiol (1985). 2002;92(5):1795-801. https://doi.org/10.1152/jappl physiol.00546.2001.

75. Bostad W, Valentino SE, McCarthy DG, Richards DL, Maclnnis MJ, MacDonald MJ, et al. Twelve weeks of sprint interval training increases peak cardiac output in previously untrained individuals. Eur J Appl Physiol. 2021;121(9):2449-58. https://doi.org/10.1007/s00421-021-04714-4.

76. Phillips BE, Kelly BM, Lilja M, Ponce-Gonzalez JG, Brogan RJ, Morris DL, et al. A practical and time-efficient high-intensity interval training program modifies cardio-metabolic risk factors in adults with risk factors for type II diabetes. Front Endocrinol (Lausanne). 2017;8:229. https://doi. org/10.3389/fendo.2017.00229.

77. Lundby C, Montero D, Joyner M. Biology of VO2 max: looking under the physiology lamp. Acta Physiol (Oxf). 2017;220(2):218-28. https://doi. org/10.1111/apha.12827.

78. Astorino TA, Edmunds RM, Clark A, King L, Gallant RA, Namm S, et al. High-intensity interval training increases cardiac output and VO2max. Med Sci Sports Exerc. 2017;49(2):265-73. https://doi.org/10.1249/MSS 0000000000001099.

79. Schaumberg MA, Jenkins DG, Janse DEJXA, Emmerton LM, Skinner TL. Oral contraceptive use dampens physiological adaptations to sprint interval training. Med Sci Sports Exerc. 2017;49(4):717-27. https://doi. org/10.1249/MSS.0000000000001171.

80. Munan M, Oliveira CLP, Marcotte-Chenard A, Rees JL, Prado CM, Riesco $E$, et al. Acute and chronic effects of exercise on continuous glucose monitoring outcomes in type 2 diabetes: a meta-analysis. Front 
Endocrinol (Lausanne). 2020;11:495. https://doi.org/10.3389/fendo. 2020.00495

81. Sylow L, Richter EA. Current advances in our understanding of exercise as medicine in metabolic disease. Curr Opin Physio. 2019;12:12-9. https://doi.org/10.1016/j.cophys.2019.04.008.

82. Brestoff JR, Clippinger B, Spinella T, von Duvillard SP, Nindl BC, Arciero PJ. An acute bout of endurance exercise but not sprint interval exercise enhances insulin sensitivity. Appl Physiol Nutr Metab. 2009;34(1):25-32. https://doi.org/10.1139/H08-126.

83. Richards JC, Johnson TK, Kuzma JN, Lonac MC, Schweder MM, Voyles $W F$, et al. Short-term sprint interval training increases insulin sensitivity in healthy adults but does not affect the thermogenic response to beta-adrenergic stimulation. J Physiol. 2010;588(Pt 15):2961-72. https:// doi.org/10.1113/jphysiol.2010.189886.

84. Metcalfe R, Fawkner S, Vollaard N. No acute effect of reduced-exertion high-intensity interval training (REHIT) on insulin sensitivity. Int J Sports Med. 2016;37(5):354-8. https://doi.org/10.1055/s-0035-1564258.

85. Ortega JF, Fernandez-Elias VE, Hamouti N, Pallares JG, Mora-Rodriguez R. Higher insulin-sensitizing response after sprint interval compared to continuous exercise. Int J Sports Med. 2015;36(3):209-14. https://doi. org/10.1055/s-0034-1389942.

86. Whyte LJ, Ferguson C, Wilson J, Scott RA, Gill JM. Effects of single bout of very high-intensity exercise on metabolic health biomarkers in overweight/obese sedentary men. Metabolism. 2013;62(2):212-9. https:// doi.org/10.1016/j.metabol.2012.07.019.

87. Durrer C, Robinson E, Wan Z, Martinez N, Hummel ML, Jenkins NT, et al. Differential impact of acute high-intensity exercise on circulating endothelial microparticles and insulin resistance between overweight/ obese males and females. PLoS ONE. 2015;10(2): e0115860. https://doi. org/10.1371/journal.pone.0115860.

88. Little JP, Jung ME, Wright AE, Wright W, Manders RJF. Effects of highintensity interval exercise versus continuous moderate-intensity exercise on postprandial glycemic control assessed by continuous glucose monitoring in obese adults. Appl Physiol Nutr Metab. 2014;39(7):83541. https://doi.org/10.1139/apnm-2013-0512.

89. Parker L, Shaw CS, Banting L, Levinger I, Hill KM, McAinch AJ, et al. Acute low-volume high-intensity interval exercise and continuous moderateintensity exercise elicit a similar improvement in 24-h glycemic control in overweight and obese adults. Front Physiol. 2016;7:661. https://doi. org/10.3389/fphys.2016.00661

90. Gillen JB, Little JP, Punthakee Z, Tarnopolsky MA, Ridell MC, Gibala MJ. Acute high-intensity interval exercise reduces the postprandial glucose response and prevalence of hyperglycaemia in patients with type 2 diabetes. Diabetes Obes Metab. 2012;14(6):575-7. https://doi.org/10. 1111/j.1463-1326.2012.01564.x.

91. Ryan BJ, Schleh MW, Ahn C, Ludzki AC, Gillen JB, Varshney P, et al. Moderate-intensity exercise and high-intensity interval training affect insulin sensitivity similarly in obese adults. J Clin Endocrinol Metab. 2020;105(8):e2941-59. https://doi.org/10.1210/clinem/dgaa345.

92. Esbjörnsson-Liljedahl M, Sundberg CJ, Norman B, Jansson E. Metabolic response in type I and type II muscle fibers during a 30-s cycle sprint in men and women. J Appl Physiol (1985). 1999;87(4):1326-32. https://doi. org/10.1152/jappl.1999.87.4.1326.

93. Esbjörnsson-Liljedahl M, Bodin K, Jansson E. Smaller muscle ATP reduction in women than in men by repeated bouts of sprint exercise. J Appl Physiol (1985). 2002;93(3):1075-83. https://doi.org/10.1152/japplphysi ol.00732.1999.

94. Tarnopolsky $\sqcup$, MacDougall JD, Atkinson SA, Tarnopolsky MA, Sutton JR. Gender differences in substrate for endurance exercise. J Appl Physiol (1985). 1990;68(1):302-8.

95. Hamadeh MJ, Devries MC, Tarnopolsky MA. Estrogen supplementation reduces whole body leucine and carbohydrate oxidation and increases lipid oxidation in men during endurance exercise. J Clin Endocrinol Metab. 2005;90(6):3592-9. https://doi.org/10.1210/jc.2004-1743.

96. Oosthuyse T, Bosch AN. The effect of the menstrual cycle on exercise metabolism: implications for exercise performance in eumenorrhoeic women. Sports Med. 2010;40(3):207-27. https://doi.org/10.2165/11317 090-000000000-00000.

97. Devries MC, Hamadeh MJ, Graham TE, Tarnopolsky MA. 17beta-estradio supplementation decreases glucose rate of appearance and disappearance with no effect on glycogen utilization during moderate intensity exercise in men. J Clin Endocrinol Metab. 2005;90(11):6218-25. https:// doi.org/10.1210/jc.2005-0926.

98. Devries MC, Hamadeh MJ, Phillips SM, Tarnopolsky MA. Menstrual cycle phase and sex influence muscle glycogen utilization and glucose turnover during moderate-intensity endurance exercise. Am J Physiol Regul Integr Comp Physiol. 2006;291(4):R1120-8. https://doi.org/10. 1152/ajpregu.00700.2005.

99. Racil G, Ben Ounis O, Hammouda O, Kallel A, Zouhal H, Chamari K, et al. Effects of high vs. moderate exercise intensity during interval training on lipids and adiponectin levels in obese young females. Eur J Appl Physiol. 2013;113(10):2531-40. https://doi.org/10.1007/ s00421-013-2689-5.

100. Maillard F, Rousset S, Pereira B, Traore A, de Pradel Del Amaze P, Boirie $Y$, et al. High-intensity interval training reduces abdominal fat mass in postmenopausal women with type 2 diabetes. Diabetes Metab. 2016;42(6):433-41. https://doi.org/10.1016/j.diabet.2016.07.031.

101. Samadi Z, Bambaeichi E, Valiani M, Shahshahan Z. Evaluation of changes in levels of hyperandrogenism, hirsutism and menstrual regulation after a period of aquatic high intensity interval training in women with polycystic ovary syndrome. Int J Prev Med. 2019;10:187. https:// doi.org/10.4103/ijpvm.IJPVM_360_18.

102. Arad AD, DiMenna FJ, Thomas N, Tamis-Holland J, Weil R, Geliebter A, et al. High-intensity interval training without weight loss improves exercise but not basal or insulin-induced metabolism in overweight/obese African American women. J Appl Physiol (1985). 2015;119(4):352-62. https://doi.org/10.1152/japplphysiol.00306.2015.

103. Sandvei M, Jeppesen PB, Stoen L, Litleskare S, Johansen E, Stensrud $T$, et al. Sprint interval running increases insulin sensitivity in young healthy subjects. Arch Physiol Biochem. 2012;118(3):139-47. https://doi. org/10.3109/13813455.2012.677454.

104. Shepherd SO, Wilson OJ, Taylor AS, Thogersen-Ntoumani C, Adlan AM, Wagenmakers AJ, et al. Low-volume high-intensity interval training in a gym setting improves cardio-metabolic and psychological health. PLoS ONE. 2015;10(9): e0139056. https://doi.org/10.1371/journal.pone.01390 56.

105. Scott SN, Shepherd SO, Hopkins N, Dawson EA, Strauss JA, Wright DJ, et al. Home-hit improves muscle capillarisation and eNOS/NAD(P) Hoxidase protein ratio in obese individuals with elevated cardiovascular disease risk. J Physiol. 2019;597(16):4203-25. https://doi.org/10.1113/ JP278062.

106. Francois ME, Durrer C, Pistawka KJ, Halperin FA, Chang C, Little JP. Combined interval training and post-exercise nutrition in type 2 diabetes: a randomized control trial. Front Physiol. 2017;8:528. https://doi.org/10. 3389/fphys.2017.00528.

107. Little JP, Gillen JB, Percival ME, Safdar A, Tarnopolsky MA, Punthakee Z, et al. Low-volume high-intensity interval training reduces hyperglycemia and increases muscle mitochondrial capacity in patients with type 2 diabetes. J Appl Physiol (1985). 2011;111(6):1554-60. https://doi.org/ 10.1152/japplphysiol.00921.2011.

108. Madsen SM, Thorup AC, Overgaard K, Jeppesen PB. High intensity interval training improves glycaemic control and pancreatic beta cell function of type 2 diabetes patients. PLOS ONE. 2015;10(8):e0133286. https://doi.org/10.1371/journal.pone.0133286.

109. Winding KM, Munch GW, lepsen UW, Van Hall G, Pedersen BK, Mortensen SP. The effect on glycaemic control of low-volume highintensity interval training versus endurance training in individuals with type 2 diabetes. Diabetes Obes Metab. 2018;20(5):1131-9. https://doi. org/10.1111/dom.13198.

110. Alvarez C, Ramirez-Campillo R, Ramirez-Velez R, Izquierdo M. Effects and prevalence of nonresponders after 12 weeks of high-intensity interval or resistance training in women with insulin resistance: a randomized trial. J Appl Physiol (1985). 2017;122(4):985-96. https://doi.org/10.1152/ japplphysiol.01037.2016.

111. Mandrup CM, Egelund J, Nyberg M, Enevoldsen LH, Kjaer A, Clemmensen $\mathrm{AE}$, et al. Effects of menopause and high-intensity training on insulin sensitivity and muscle metabolism. Menopause. 2018;25(2):16575. https://doi.org/10.1097/GME.0000000000000981.

112. Kiel IA, Lundgren KM, Morkved S, Kjotrod SB, Salvesen O, Romundstad $L B$, et al. Women undergoing assisted fertilisation and highintensity interval training: a pilot randomised controlled trial. BMJ 
Open Sport Exerc Med. 2018;4(1):e000387. https://doi.org/10.1136/ bmjsem-2018-000387.

113. Holloszy JO. Biochemical adaptations in muscle. J Biol Chem. 1967;242(9):2278-82. https://doi.org/10.1016/s0021-9258(18)96046-1.

114. Burgomaster KA, Hughes SC, Heigenhauser GJ, Bradwell SN, Gibala MJ. Six sessions of sprint interval training increases muscle oxidative potential and cycle endurance capacity in humans. J Appl Physiol (1985). 2005;98(6):1985-90. https://doi.org/10.1152/japplphysiol.01095.2004.

115. Burgomaster KA, Heigenhauser GJ, Gibala MJ. Effect of short-term sprint interval training on human skeletal muscle carbohydrate metabolism during exercise and time-trial performance. J Appl Physiol (1985). 2006;100(6):2041-7. https://doi.org/10.1152/japplphysiol.01220.2005.

116. Gibala MJ, Little JP, van Essen M, Wilkin GP, Burgomaster KA, Safdar A, et al. Short-term sprint interval versus traditional endurance training: similar initial adaptations in human skeletal muscle and exercise performance. J Physiol. 2006;575(Pt 3):901-11. https://doi.org/10.1113/jphys iol.2006.112094

117. Little JP, Safdar A, Wilkin GP, Tarnopolsky MA, Gibala MJ. A practical model of low-volume high-intensity interval training induces mitochondrial biogenesis in human skeletal muscle: potential mechanisms. J Physiol. 2010;588(Pt 6):1011-22. https://doi.org/10.1113/jphysiol.2009. 181743.

118. Jacobs RA, Fluck D, Bonne TC, Burgi S, Christensen PM, Toigo M, et al. Improvements in exercise performance with high-intensity interval training coincide with an increase in skeletal muscle mitochondrial content and function. J Appl Physiol (1985). 2013;115(6):785-93. https://doi.org/10.1152/japplphysiol.00445.2013.

119. Larsen S, Nielsen J, Hansen CN, Nielsen LB, Wibrand F, Stride N, et al. Biomarkers of mitochondrial content in skeletal muscle of healthy young human subjects. J Physiol. 2012;590(14):3349-60. https://doi.org/10. 1113/jphysiol.2012.230185.

120. Medeiros DM. Assessing mitochondria biogenesis. Methods. 2008;46(4):288-94. https://doi.org/10.1016/j.ymeth.2008.09.026

121. Tan R, Nederveen JP, Gillen JB, Joanisse S, Parise G, Tarnopolsky MA, et al. Skeletal muscle fiber-type-specific changes in markers of capillary and mitochondrial content after low-volume interval training in overweight women. Physiol Rep. 2018;6(5):e13597. https://doi.org/10.14814/phy2. 13597.

122. Edgett BA, Bonafiglia JT, Baechler BL, Quadrilatero J, Gurd BJ. The effect of acute and chronic sprint-interval training on LRP130, SIRT3, and PGC-1alpha expression in human skeletal muscle. Physiol Rep. 2016.4(17):e12879. https://doi.org/10.14814/phy2.12879.

123. Granata C, Oliveira RS, Little JP, Renner K, Bishop DJ. Training intensity modulates changes in PGC-1alpha and p53 protein content and mitochondrial respiration, but not markers of mitochondrial content in human skeletal muscle. FASEB J. 2016;30(2):959-70. https://doi.org/10. 1096/f.15-276907.

124. Fiorenza M, Lemminger AK, Marker M, Eibye K, laia FM, Bangsbo J, et al. High-intensity exercise training enhances mitochondrial oxidative phosphorylation efficiency in a temperature-dependent manner in human skeletal muscle: implications for exercise performance. FASEB J. 2019;33(8):8976-89. https://doi.org/10.1096/f..201900106RRR.

125. Gillen JB, Martin BJ, MacInnis MJ, Skelly LE, Tarnopolsky MA, Gibala MJ. Twelve weeks of sprint interval training improves indices of cardiometabolic health similar to traditional endurance training despite a five-fold lower exercise volume and time commitment. PLOS ONE. 2016;11(4):e0154075. https://doi.org/10.1371/journal.pone.0154075.

126. Cocks M, Shaw CS, Shepherd SO, Fisher JP, Ranasinghe AM, Barker TA, et al. Sprint interval and endurance training are equally effective in increasing muscle microvascular density and eNOS content in sedentary males. J Physiol. 2013;591(3):641-56. https://doi.org/10.1113/jphys iol.2012.239566.

127. Boyd JC, Simpson CA, Jung ME, Gurd BJ. Reducing the intensity and volume of interval training diminishes cardiovascular adaptation but not mitochondrial biogenesis in overweight/obese men. PLoS ONE. 2013:8(7):e68091. https://doi.org/10.1371/journal.pone.0068091.

128. Scribbans TD, Edgett BA, Vorobej K, Mitchell AS, Joanisse SD, Matusiak $J B$, et al. Fibre-specific responses to endurance and low volume high intensity interval training: striking similarities in acute and chronic adaptation. PLoS ONE. 2014;9(6):e98119. https://doi.org/10.1371/journ al.pone.0098119.
129. Wyckelsma VL, Venckunas T, Brazaitis M, Gastaldello S, Snieckus A, Eimantas $\mathrm{N}$, et al. Vitamin $\mathrm{C}$ and $\mathrm{E}$ treatment blunts sprint interval training-induced changes in inflammatory mediator-, calcium-, and mitochondria-related signaling in recreationally active elderly humans. Antioxidants (Basel). 2020;9(9):879. https://doi.org/10.3390/antiox9090 879.

130. Talanian JL, Galloway SD, Heigenhauser GJ, Bonen A, Spriet LL. Two weeks of high-intensity aerobic interval training increases the capacity for fat oxidation during exercise in women. J Appl Physiol (1985). 2007;102(4):1439-47. https://doi.org/10.1152/japplphysiol.01098.2006.

131. Talanian JL, Holloway GP, Snook LA, Heigenhauser GJ, Bonen A, Spriet $\mathrm{LL}$. Exercise training increases sarcolemmal and mitochondrial fatty acid transport proteins in human skeletal muscle. Am J Physiol Endocrinol Metab. 2010;299(2):E180-8. https://doi.org/10.1152/ajpendo.00073. 2010.

132. Nyberg M, Egelund J, Mandrup CM, Andersen CB, Hansen K, Hergel IF, et al. Leg vascular and skeletal muscle mitochondrial adaptations to aerobic high-intensity exercise training are enhanced in the early postmenopausal phase. J Physiol. 2017;595(9):2969-83. https://doi.org/ 10.1113/JP273871.

133. Burgomaster KA, Howarth KR, Phillips SM, Rakobowchuk M, Macdonald MJ, McGee SL, et al. Similar metabolic adaptations during exercise after low volume sprint interval and traditional endurance training in humans. J Physiol. 2008;586(1):151-60. https://doi.org/10.1113/jphysiol. 2007.142109.

134. Baekkerud FH, Solberg F, Leinan IM, Wisloff U, Karlsen T, Rognmo O. Comparison of three popular exercise modalities on $\mathrm{V} O 2$ max in overweight and obese. Med Sci Sports Exerc. 2016;48(3):491-8. https://doi. org/10.1249/MSS.00000000000000777.

135. Koh HE, Ortenblad N, Winding KM, Hellsten Y, Mortensen SP, Nielsen $J$. High-intensity interval, but not endurance, training induces muscle fiber type-specific subsarcolemmal lipid droplet size reduction in type 2 diabetic patients. Am J Physiol Endocrinol Metab. 2018;315(5):E872-84. https://doi.org/10.1152/ajpendo.00161.2018.

136. Shepherd SO, Cocks M, Tipton KD, Ranasinghe AM, Barker TA, Burniston $J \mathrm{G}$, et al. Sprint interval and traditional endurance training increase net intramuscular triglyceride breakdown and expression of perilipin 2 and 5. J Physiol. 2013;591(3):657-75. https://doi.org/10.1113/jphysiol.2012. 240952.

137. Shepherd SO, Cocks M, Meikle PJ, Mellett NA, Ranasinghe AM, Barker TA, et al. Lipid droplet remodelling and reduced muscle ceramides following sprint interval and moderate-intensity continuous exercise training in obese males. Int J Obes (Lond). 2017;41(12):1745-54. https://doi.org/ 10.1038/ijo.2017.170.

138. Chrois KM, Dohlmann TL, Sogaard D, Hansen CV, Dela F, Helge JW, et al. Mitochondrial adaptations to high intensity interval training in older females and males. Eur J Sport Sci. 2020;20(1):135-45. https://doi.org/ 10.1080/17461391.2019.1615556.

139. Egan B, Zierath JR. Exercise metabolism and the molecular regulation of skeletal muscle adaptation. Cell Metab. 2013;17(2):162-84. https://doi. org/10.1016/j.cmet.2012.12.012.

140. Tobias IS, Lazauskas KK, Siu J, Costa PB, Coburn JW, Galpin AJ. Sex and fiber type independently influence AMPK, TBC1D1, and TBC1D4 at rest and during recovery from high-intensity exercise in humans. J Appl Physiol (1985). 2020;128(2):350-61. https://doi.org/10.1152/japplphysi ol.00704.2019.

141. Skelly LE, Gillen JB, Maclnnis MJ, Martin BJ, Safdar A, Akhtar M, et al. Effect of sex on the acute skeletal muscle response to sprint interval exercise. Exp Physiol. 2017;102(3):354-65. https://doi.org/10.1113/ EP086118.

142. Nuzzo J. Volunteer bias and female participation in exercise and sports science research. Quest. 2021;73(1):82-101. https://doi.org/10.1080/ 00336297.2021.1875248.

143. Wilson R, Adams NL, Pyke KE. Inclusion of female participants in cardiovascular research: a case study of Ontario NSERC-funded programs. Appl Physiol Nutr Metab. 2020:45(8):911-4.

144. Valdes CT, Elkind-Hirsch KE. Intravenous glucose tolerance test-derived insulin sensitivity changes during the menstrual cycle. J Clin Endocrinol Metab. 1991;72(3):642-6. https://doi.org/10.1210/jcem-72-3-642.

145. Fu MH, Maher AC, Hamadeh MJ, Ye C, Tarnopolsky MA. Exercise, sex, menstrual cycle phase, and 17beta-estradiol influence 
metabolism-related genes in human skeletal muscle. Physiol Genomics. 2009:40(1):34-47. https://doi.org/10.1152/physiolgenomics.00115.2009.

146. United Nations, Department of Economic and Social Affairs, Population Division. Contraceptive Use by Method 2019: Data Booklet (ST/ESA/ SER.A/435). 2019.

147. Sims ST, Heather AK. Myths and Methodologies: reducing scientific design ambiguity in studies comparing sexes and/or menstrual cycle phases. Exp Physiol. 2018;103(10):1309-17. https://doi.org/10.1113/ EP086797.

148. Janse DEJX, Thompson B, Han A. Methodological recommendations for menstrual cycle research in sports and exercise. Med Sci Sports Exerc 2019;51(12):2610-7. https://doi.org/10.1249/MSS.0000000000002073.

149. Elliott-Sale KJ, Minahan CL, de Jonge X, Ackerman KE, Sipila S, Constantini NW, et al. Methodological considerations for studies in sport and exercise science with women as participants: a working guide for standards of practice for research on women. Sports Med. 2021;51(5):843-61. https://doi.org/10.1007/s40279-021-01435-8.

150. Lundsgaard AM, Kiens B. Gender differences in skeletal muscle substrate metabolism—-molecular mechanisms and insulin sensitivity. Front Endocrinol (Lausanne). 2014;5:195. https://doi.org/10.3389/fendo. 2014.00195.

151. Montero D, Madsen K, Meinild-Lundby AK, Edin F, Lundby C. Sexual dimorphism of substrate utilization: differences in skeletal muscle mitochondrial volume density and function. Exp Physiol. 2018;103(6):851-9. https://doi.org/10.1113/EP087007.

152. Ogawa T, Spina RJ, Martin WH 3rd, Kohrt WM, Schechtman KB, Holloszy $\mathrm{JO}$, et al. Effects of aging, sex, and physical training on cardiovascular responses to exercise. Circulation. 1992;86(2):494-503.

153. Diaz-Canestro C, Montero D. Sex dimorphism of VO2max trainability: a systematic review and meta-analysis. Sports Med. 2019;49(12):1949-56. https://doi.org/10.1007/s40279-019-01180-z.

154. Carrick-Ranson G, Hastings JL, Bhella PS, Shibata S, Fujimoto N, Palmer $D$, et al. The effect of age-related differences in body size and composition on cardiovascular determinants of VO2max. J Gerontol A Biol Sci Med Sci. 2013;68(5):608-16. https://doi.org/10.1093/gerona/gls220.

155. Tarnopolsky MA. Sex differences in exercise metabolism and the role of 17-beta estradiol. Med Sci Sports Exerc. 2008;40(4):648-54. https://doi. org/10.1249/MSS.0b013e31816212ff.

156. Chrzanowski-Smith OJ, Edinburgh RM, Smith E, Thomas MP, Walhin JP, Koumanov F, et al. Resting skeletal muscle PNPLA2 (ATGL) and CPT1B are associated with peak fat oxidation rates in men and women but do not explain observed sex differences. Exp Physiol. 2021;106(5):1208-23. https://doi.org/10.1113/EP089431.

157. Mann T, Lamberts RP, Lambert MI. Methods of prescribing relative exercise intensity: physiological and practical considerations. Sports Med. 2013;43(7):613-25. https://doi.org/10.1007/s40279-013-0045-x.

158. Hottenrott L, Mohle M, Ide A, Ketelhut S, Stoll O, Hottenrott K. Recovery from different high-intensity interval training protocols: comparing well-trained women and men. Sports (Basel). 2021;9(3):34. https://doi. org/10.3390/sports9030034.

159. Schmitz B, Niehues H, Thorwesten L, Klose A, Kruger M, Brand SM Sex differences in high-intensity interval training-are HIIT protocols interchangeable between females and males? Front Physiol. 2020;11:38 https://doi.org/10.3389/fphys.2020.00038.

160. Alkhatib A, Hsieh MJ, Kuo CH, Hou CW. Caffeine optimizes HIIT benefits on obesity-associated metabolic adversity in women. Med Sci Sports Exerc. 2020;52(8):1793-800. https://doi.org/10.1249/MSS.0000000000 002311.

161. Harris E, Rakobowchuk M, Birch KM. Sprint interval and sprint continuous training increases circulating CD34+ cells and cardio-respiratory fitness in young healthy women. PLoS ONE. 2014;9(9): e108720. https:// doi.org/10.1371/journal.pone.0108720.

162. Banitalebi E, Kazemi A, Faramarzi M, Nasiri S, Haghighi MM. Effects of sprint interval or combined aerobic and resistance training on myokines in overweight women with type 2 diabetes: a randomized controlled trial. Life Sci. 2019;217:101-9. https://doi.org/10.1016/j.lfs. 2018.11.062.

163. Esbjörnsson Liljedahl M, Holm I, Sylvén C, Jansson E. Different responses of skeletal muscle following sprint training in men and women. Eur J Appl Physiol Occup Physiol. 1996;74(4):375-83. https://doi.org/10.1007/ BF02226935.
164. Smith-Ryan AE, Trexler ET, Wingfield HL, Blue MN. Effects of highintensity interval training on cardiometabolic risk factors in overweight/ obese women. J Sports Sci. 2016;34(21):2038-46. https://doi.org/10. 1080/02640414.2016.1149609.

165. Ready AE, Eynon RB, Cunningham DA. Effect of interval training and detraining on anaerobic fitness in women. Can J Appl Sport Sci. 1981;6(3):114-8.

166. Alvarez C, Ramirez-Campillo R, Ramirez-Velez R, Izquierdo M. Prevalence of non-responders for glucose control markers after 10 weeks of highintensity interval training in adult women with higher and lower insulin resistance. Front Physiol. 2017;8:479. https://doi.org/10.3389/fphys. 2017.00479.

167. Ho TY, Redmayne GP, Tran A, Liu D, Butlin M, Avolio A, et al. The effect of interval sprinting exercise on vascular function and aerobic fitness of post-menopausal women. Scand J Med Sci Sports. 2020;30(2):312-21. https://doi.org/10.1111/sms.13574.

168. Zhang H, Tong TK, Kong Z, Shi Q, Liu Y, Nie J. Exercise training-induced visceral fat loss in obese women: the role of training intensity and modality. Scand J Med Sci Sports. 2021;31(1):30-43. https://doi.org/10. 1111/sms.13803.

\section{Publisher's Note}

Springer Nature remains neutral with regard to jurisdictional claims in published maps and institutional affiliations.

\section{Submit your manuscript to a SpringerOpen ${ }^{\circ}$ journal and benefit from:}

- Convenient online submission

- Rigorous peer review

- Open access: articles freely available online

- High visibility within the field

Retaining the copyright to your article

Submit your next manuscript at $\boldsymbol{\nabla}$ springeropen.com 